\title{
Life cycle assessment applying planetary and regional boundaries to the process level: a model case study
}

Bjørn, Anders; Sim, Sarah; King, Henry; Patouillard, Laure; Margni, Manuele ; Hauschild, Michael Zwicky; Ryberg, Morten

Published in:

International Journal of Life Cycle Assessment

Link to article, DOI:

$10.1007 / \mathrm{s} 11367-020-01823-8$

Publication date:

2020

Document Version

Peer reviewed version

Link back to DTU Orbit

Citation (APA):

Bjørn, A., Sim, S., King, H., Patouillard, L., Margni, M., Hauschild, M. Z., \& Ryberg, M. (2020). Life cycle assessment applying planetary and regional boundaries to the process level: a model case study. International Journal of Life Cycle Assessment, 25(11), 2241-2254. https://doi.org/10.1007/s11367-020-01823-8

\section{General rights}

Copyright and moral rights for the publications made accessible in the public portal are retained by the authors and/or other copyright owners and it is a condition of accessing publications that users recognise and abide by the legal requirements associated with these rights.

- Users may download and print one copy of any publication from the public portal for the purpose of private study or research.

- You may not further distribute the material or use it for any profit-making activity or commercial gain

- You may freely distribute the URL identifying the publication in the public portal 
Bjørn, A., Sim, S., King, H., Patouillard, L., Margni, M., Hauschild, M. Z., \& Ryberg, M. (2020). Life cycle assessment applying planetary and regional boundaries to the process level: a model case study.

The International Journal of Life Cycle Assessment, 25(11), 2241-2254. https://doi.org/10.1007/s11367-020-01823-8

\section{Life cycle assessment applying planetary and regional boundaries to the process level: a model case study}

Bjørn, Anders ${ }^{1}$, Sim, Sarah ${ }^{2}$, King, Henry ${ }^{2}$, Patouillard, Laure ${ }^{1}$, Margni, Manuele ${ }^{1}$, Hauschild, Michael Zwicky ${ }^{3}$, Ryberg, Morten ${ }^{3}$

* corresponding author: Email: anders.bjoern@concordia.ca

Affiliations:

${ }^{1}$ CIRAIG, Mathematical and Industrial Engineering Department, Polytechnique Montreal, C.P. 6079, succ. Centre-Ville, Montréal, QC H3C 3A7, Canada

${ }^{2}$ Unilever Safety and Environmental Assurance Centre, Unilever R\&D, Colworth Science Park, Sharnbrook, MK44 1LQ, UK.

${ }^{3}$ Quantitative Sustainability Assessment group, Department of Technology, Management and Economics, Technical University of Denmark, Produktionstorvet, Building 424, 2800 Kgs. Lyngby, Denmark. 
Bjørn, A., Sim, S., King, H., Patouillard, L., Margni, M., Hauschild, M. Z., \& Ryberg, M. (2020). Life cycle assessment applying planetary and regional boundaries to the process level: a model case study.

Life cycle assessment applying planetary and regional boundaries to the process level: a model case study

${ }^{3}$ Hauschild ${ }^{3}$, Morten Ryberg ${ }^{3}$

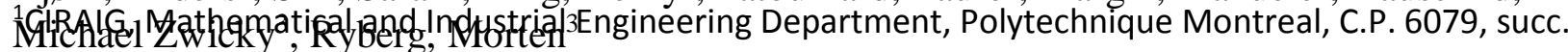

7 Centre-Ville, Montréal, QC H3C 3A7, Canada.

* corresponding author: Email: anders.bjoern@concordia.ca

8 2Unilever Safety and Environmental Assurance Centre, Unilever R\&D, Colworth Science Park, Affiliations:

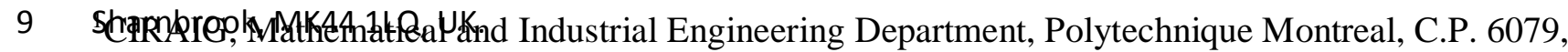

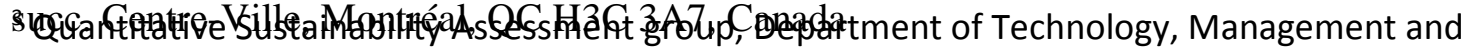

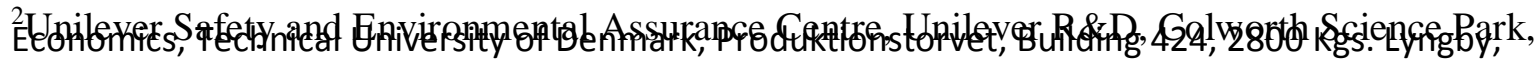

${ }^{3}$ Quantitative Sustainability Assessment group, Department of Technology, Management and 13 ÉEbrespies, ding Denmark.

\section{Abstract:}

Pyfpopeinthe Thersanetary boundaries framework contains regional boundaries in addition to global boundaries. Geographically resolved methods to assess regional environmental impacts are therefore needed. Existing Planetary boundaries-based life cycle assessment (PB-LCA) methods have limited geographical resolution or are not applicable to full product systems, due to high spatial requirements on inventory data. Here, we enable PB-LCA of full product systems across a comprehensive set of regional and global PB impact categories.

Methods: We propose comparing environmental impacts of individual processes within a product system to assigned shares of regional or global safe operating space (SOS). This is followed by aggregation of process-level results so that accumulated exceedance of assigned SOS is derived across 
Bjørn, A., Sim, S., King, H., Patouillard, L., Margni, M., Hauschild, M. Z., \& Ryberg, M. (2020). Life cycle assessment applying planetary and regional boundaries to the process level: a model case study.

25 the entire life cycle. We then present a procedure for aggregating geographically resolved

characterization factors (CFs) and SOS to country, continent and global levels, ensuring compatibility

27 with typical life cycle inventory results. We then apply the new techniques to a model laundry case

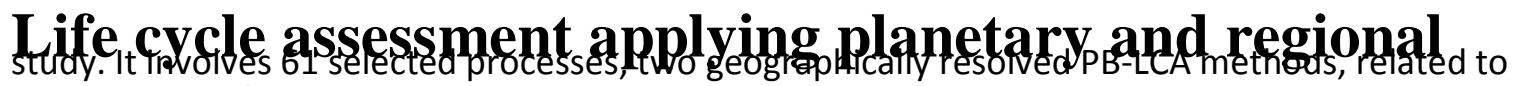 boundaries to the process level: a model case study}

29 impacts from freshwater use and nitrogen emissions, and a largely spatially generic PB-LCA method that Bjørn, Anders ${ }^{1}$, Sim, Sarah ${ }^{2}$, King, Henry ${ }^{2}$, Patouillard, Laure ${ }^{1}$, Margni, Manuele ${ }^{1}$, Hauschild,

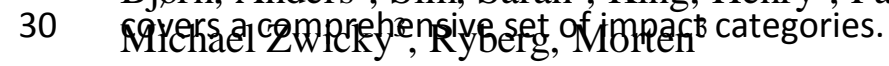

31 Results and discussion: The calculation of accumulated exceedance of assigned SOS may help inform * corresponding author: Email: anders.bjoern@concordia.ca

32 decisions about where in a life cycle to focus impact reduction efforts most urgently. The number of Affiliations:

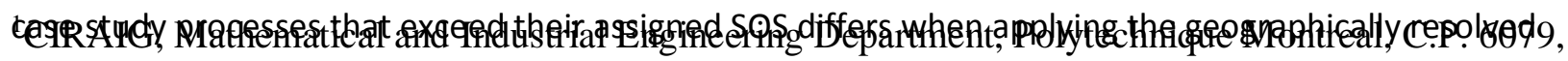

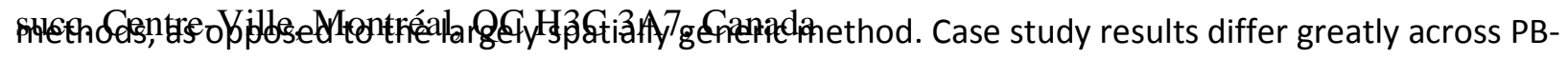

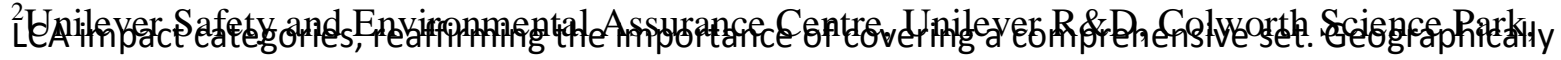

Sharnbrook, MK44 1LQ, UK.

resolved methods are needed for all regional impact categories and software support would be

${ }^{3}$ Quantitative Sustainability Assessment group, Department of Technology, Management and

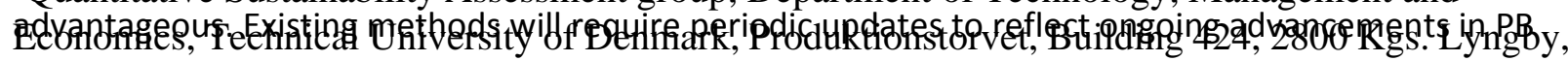

Denmark

science. Best practice approaches or a consensus for assigning regional SOS to processes are needed.

39 Conclusions and outlook: Our study provides a step towards greater operability of geographically

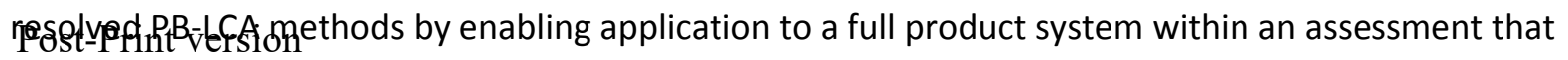

covers a comprehensive set of impact categories. The case study application shows potential advantages

of the process-level approach and points to the need for quantifying uncertainties in such assessments.

Future studies should seek to explore the potential role of PB-LCA in decision-support compared to

conventional LCA.

\section{Keywords}

47 PB-LCA; planetary boundaries; safe operating space; spatialization; CF aggregation; Biogeochemical

48 flows; Freshwater use. 
Bjørn, A., Sim, S., King, H., Patouillard, L., Margni, M., Hauschild, M. Z., \& Ryberg, M. (2020). Life cycle assessment applying planetary and regional boundaries to the process level: a model case study.

\section{Introduction}

50 The Planetary boundaries (PBs) concept is based on the idea that there are limits to the Earth's capacity

51 to assimilate environmental impacts whilst maintaining the Holocene-like state in which human

52 civilizations have developed (Rockström et al., 2009a; Steffen et al., 2015). In its most recent version

53 (Steffen et al., 2015), the PBs framework contains nine Earth-system processes (somewhat similar to

54 impact categories in LCA), for which there are currently seven quantified PBs and three sets of regional

55 boundaries (see Figure 1). For each Earth-system process, a "safe operating space" (SOS) can be defined

56 as the distance between a boundary (regional or global) and a reference value, usually representing pre-

57 industrial conditions. Boundaries and reference values are quantified using a variety of techniques from

58 Earth-system science (Steffen et al., 2015). A Planetary boundaries-based life cycle assessment (PB-LCA)

59 links planetary and regional SOS to life cycle inventories ( $\mathrm{LCls}$ ) via dedicated characterisation factors

60 (CFs) (Fang et al., 2015; Ryberg et al., 2016). In such an assessment, a product system is commonly

61 considered environmentally sustainable if its environmental impact does not exceed its assigned share

62 of the SOS for any PB impact category. Several sharing principles have been applied in the PB-LCA

63 literature to assign shares of SOS and they all require knowledge about the other production or

64 consumption activities that affect the PB impact categories (Bjørn et al., 2020a). In the illustrative

65 example of Figure 1, the product system is judged to be environmentally unsustainable. This is because

66 it exceeds the assigned safe operating space for five of the nine PB impact categories (or Earth-system

67 processes), with respect to a hypothetical sharing principle.

68 
Bjørn, A., Sim, S., King, H., Patouillard, L., Margni, M., Hauschild, M. Z., \& Ryberg, M. (2020). Life cycle assessment applying planetary and regional boundaries to the process level: a model case study.

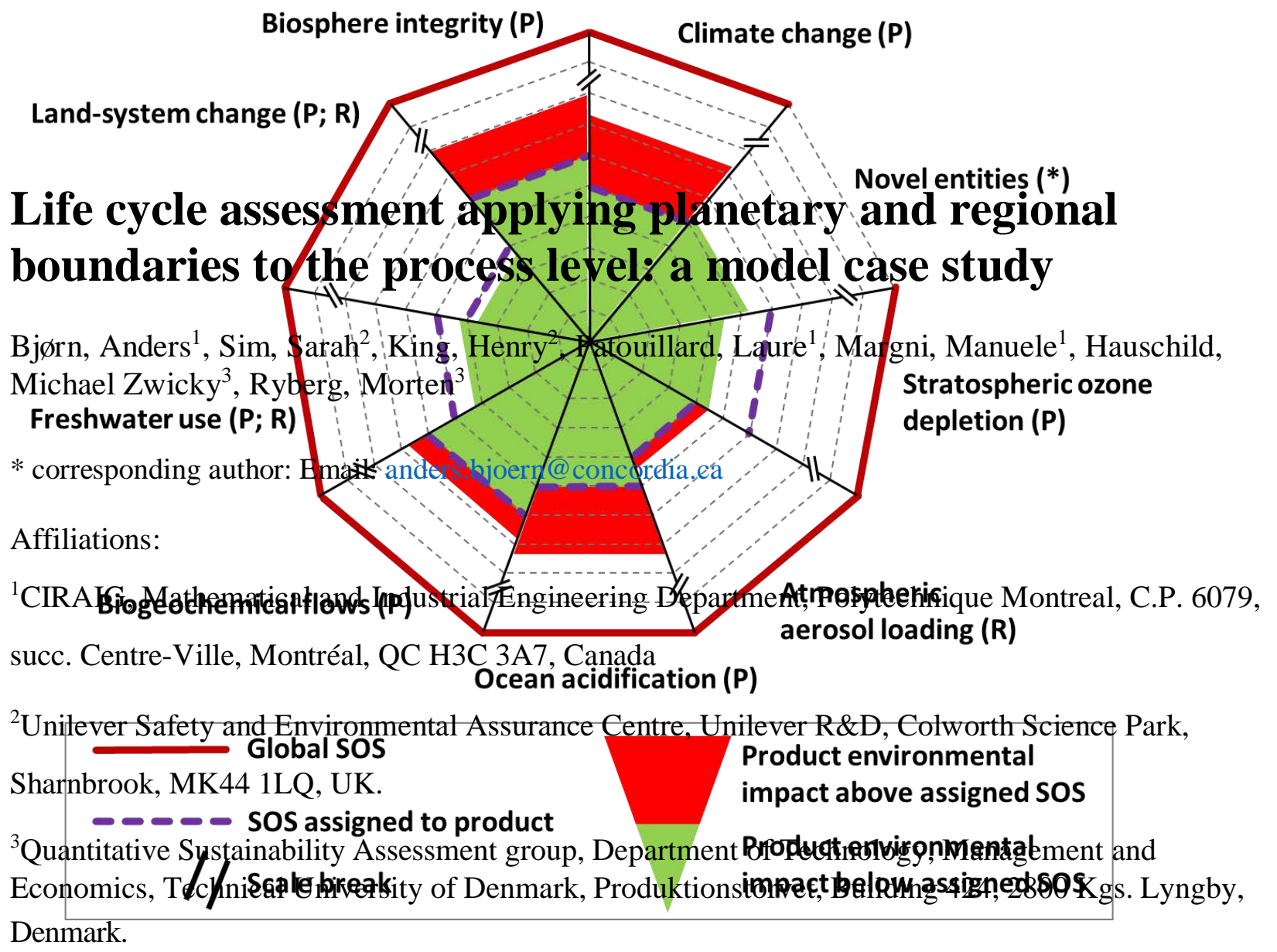

Figure 1: Illustrative example of the common PB-LCA approach according to the nine impact categories

(or Earth-system processes) of Steffen et al. (2015). Several impact indicators may exist for each impact category (not shown). The environmental impacts and assigned safe operating space are illustrative and uncertainties are not covered. The letters in parenthesis after each impact category indicate whether Steffen et al. (2015) identify a planetary $(P)$ boundary and/or a regional set of boundaries (R). *There is no boundary defined for Novel entities in Steffen et al. (2015).

The recent comprehensive PB-based life-cycle impact assessment method of Ryberg et al. (2018a) covers seven impact categories (Climate change, Stratospheric ozone depletion, Atmospheric aerosol loading, Ocean acidification, Biogeochemical flows, Freshwater use and Land-system change), including the three with regional boundaries (see Figure 1). The method translates annual elementary flows from 
Bjørn, A., Sim, S., King, H., Patouillard, L., Margni, M., Hauschild, M. Z., \& Ryberg, M. (2020). Life cycle assessment applying planetary and regional boundaries to the process level: a model case study.

81 a product system to changes in the value of the PB "control variables" (Steffen et al., 2015) adopted as

impact indicators. In a subsequent case study, Ryberg et al. (2018b) applied their method with several

sharing principles for assigning SOS to a product. These principles reflect concerns such as equality boundaries to the process level: a model case study

method of Ryberg et al. (2018a) is comprehensive and relatively easy to apply to LCl results, a key Bjørn, Anders ${ }^{1}$, Sim, Sarah ${ }^{2}$, King, Henry ${ }^{2}$, Patouillard, Laure ${ }^{1}$, Margni, Manuele ${ }^{1}$, Hauschild,

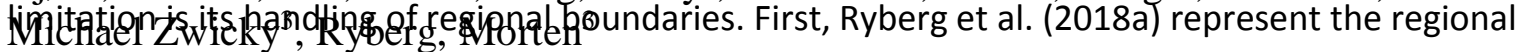

boundaries for Freshwater use and Land-system change using spatial archetypes rather than * corresponding author: Email: anders.bjoern@concordia.ca

geographical regions. The archetypes are based on aridity for Freshwater use and biomes for LandAffiliations:

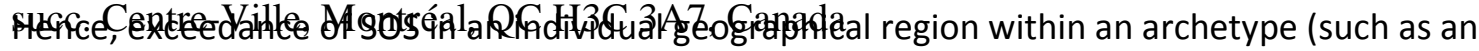

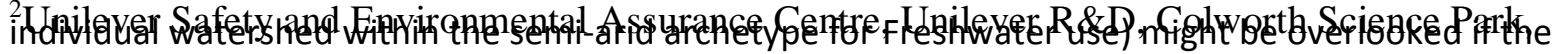

Sharnbrook, MK44 1LQ, UK.

92 aggregate impact for the regions covered by the archetype remains below the single SOS. Second, ${ }^{3}$ Quantitative Sustainability Assessment group, Department of Technology, Management and

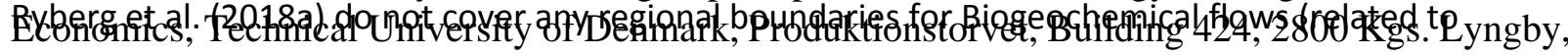

Denmark.

94 phosphorous and nitrogen cycles (Rockström et al., 2009b; Steffen et al., 2015)), even though the

quantity of nutrients that the Earth system can sustain greatly depends on their regional distribution

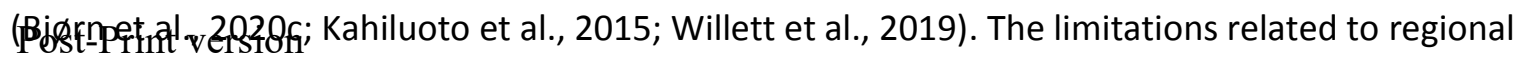

boundaries of the Ryberg et al. (2018a) method are problematic, considering the role of so-called

keystone regions in maintaining a stable Earth system (Gleeson et al., 2020) and the growing

understanding of how regional state shifts in ecosystems may propagate to the global scale (Bjørn et al.,

2019; Gleeson et al., 2020; Lenton et al., 2008; Rocha et al., 2018).

Geographically resolved PB-LCA methods may address these limitations. Such methods contain a set of spatial units (such as watersheds or grid cells) with an equivalent set of safe operating space (SOS), for each impact indicator. For each of these spatial units there is a specific CF or, in cases where elementary 
Bjørn, A., Sim, S., King, H., Patouillard, L., Margni, M., Hauschild, M. Z., \& Ryberg, M. (2020). Life cycle assessment applying planetary and regional boundaries to the process level: a model case study.

107

108

109

110

17

18

19

20

21

22

flows impact more than one spatial unit (for example, due to substance fate processes), there is a specific set of CFs. The recent geographically resolved PB-LCA methods for the impact categories Freshwater use (Bjørn et al., 2020b) and the nitrogen part of Biogeochemical flows (Bjørn et al., 2020c) provide CFs and SOS for thousands of spatial units. Due to their relatively high geographical resolution, these new methods challenge the predominant approach in PB-LCA of comparing (for a given impact category) a product system's aggregated environmental impact to an assigned share of a single global 111 SOS, as illustrated in Figure 1. Instead, the new methods enable a "process-level approach", in which the 112 environmental impacts of individual processes in a product system are compared to their assigned share 113 of the SOS for the regions they impact. So far, the geographically resolved methods (Bjørn et al., 2020c, $1142020 b)$ have only been applied to processes whose locations are known with great precision. However, 115 it is rarely possible to obtain this level of spatial resolution across an entire product life cycle. Also, the 116 process-level approach has not yet been applied within a PB-LCA method that covers all PB impact 117 categories (regional and global). In addition, full product system application requires a way of 118 aggregating the process-level results across the life cycle for each impact category to help inform 119 decisions about where in a life cycle to focus impact reduction efforts most urgently.

121 Here, we make two novel methodological contributions and apply them to a model case study. First, we 122 extend the process-level PB-LCA approach for application to the full life cycle and across a 123 comprehensive set of regional and global PB impact categories (Section 2.1). Second, we enable the use 124 of geographically resolved PB-LCA methods within the extended process-level approach, by presenting a 125 new procedure for aggregating CFs and SOS to match the different levels of spatial resolution 126 encountered in a full LCl (Section 2.2). We then construct a process-level PB-LCA case study (Section 2.3) 127 applying these two methodological contributions with three existing PB-LCA methods (Bjørn et al., 128 2020c, 2020b; Ryberg et al., 2018b). We present case study results (Section 3) and focus on three 
Bjørn, A., Sim, S., King, H., Patouillard, L., Margni, M., Hauschild, M. Z., \& Ryberg, M. (2020). Life cycle assessment applying planetary and regional boundaries to the process level: a model case study.

aspects in the ensuing discussion: 1) the additional insights gained from full life cycle application of two

geographically resolved PB-LCA methods (for Freshwater use and the nitrogen part of Biogeochemical

flows) compared to application only to those processes whose locations are known with great precision

(Section 4.1); 2) the influence on results of applying the geographically resolved methods for those two

PB impact categories vs. applying differently resolved methods (spatially generic or based on

archetypes) (Section 4.2); 3) the insights gained from covering a comprehensive set of PB impact

categories, beyond the two noted above (Section 4.3).

\section{Methods}

The meaning of all variables and their subscripts used in the equations of this section are given in Table 1391

Table 1: Meaning of variables and their subscripts.

\begin{tabular}{|l|l|}
\hline Variables & Meaning \\
\hline A & Area of a spatial unit or aggregated region. \\
\hline AE.aSOS & Accumulated exceedance of assigned (share of) safe operating space. \\
\hline aSOS & Assigned (share of) safe operating space. \\
\hline CF & Characterization factor. \\
\hline EI & Environmental impact. \\
\hline F & Annual quantity of an elementary flow taking place within a spatial unit. \\
\hline Occ.aSOS & Occupation of assigned (share of) safe operating space. \\
\hline M & Mass of an elementary flow for one unit of a process' reference flow. \\
\hline$Q$ & Quantity of reference flow of process $x$ required for the functional unit of a product system. \\
\hline SOS & Safe operating space. \\
\hline SPF & $\begin{array}{l}\text { Spatial proportionality factor (used as a weighting factor when calculating the CF of an } \\
\text { aggregated region by averaging over CFs of individual spatial units within). }\end{array}$ \\
\hline Subscripts & \\
\hline$\cap$ & Intersection between a spatial unit and an aggregated region. \\
\hline$e$ & Elementary flow, specified according to an environmental compartment. \\
\hline$i$ & Spatial unit in which an elementary flow occurs. \\
\hline$I$ & Aggregated region in which an elementary flow occurs. \\
\hline$j$ & Impacted spatial unit. \\
\hline$J$ & Impacted aggregated region. \\
\hline$k$ & Impact indicator. \\
\hline$s$ & Sharing principle. \\
\hline$x$ & Process. \\
\hline
\end{tabular}


Bjørn, A., Sim, S., King, H., Patouillard, L., Margni, M., Hauschild, M. Z., \& Ryberg, M. (2020). Life cycle assessment applying planetary and regional boundaries to the process level: a model case study.

2.1. Extended process-level PB-LCA

Below, we present the two assessment steps as illustrated in Figure 2.

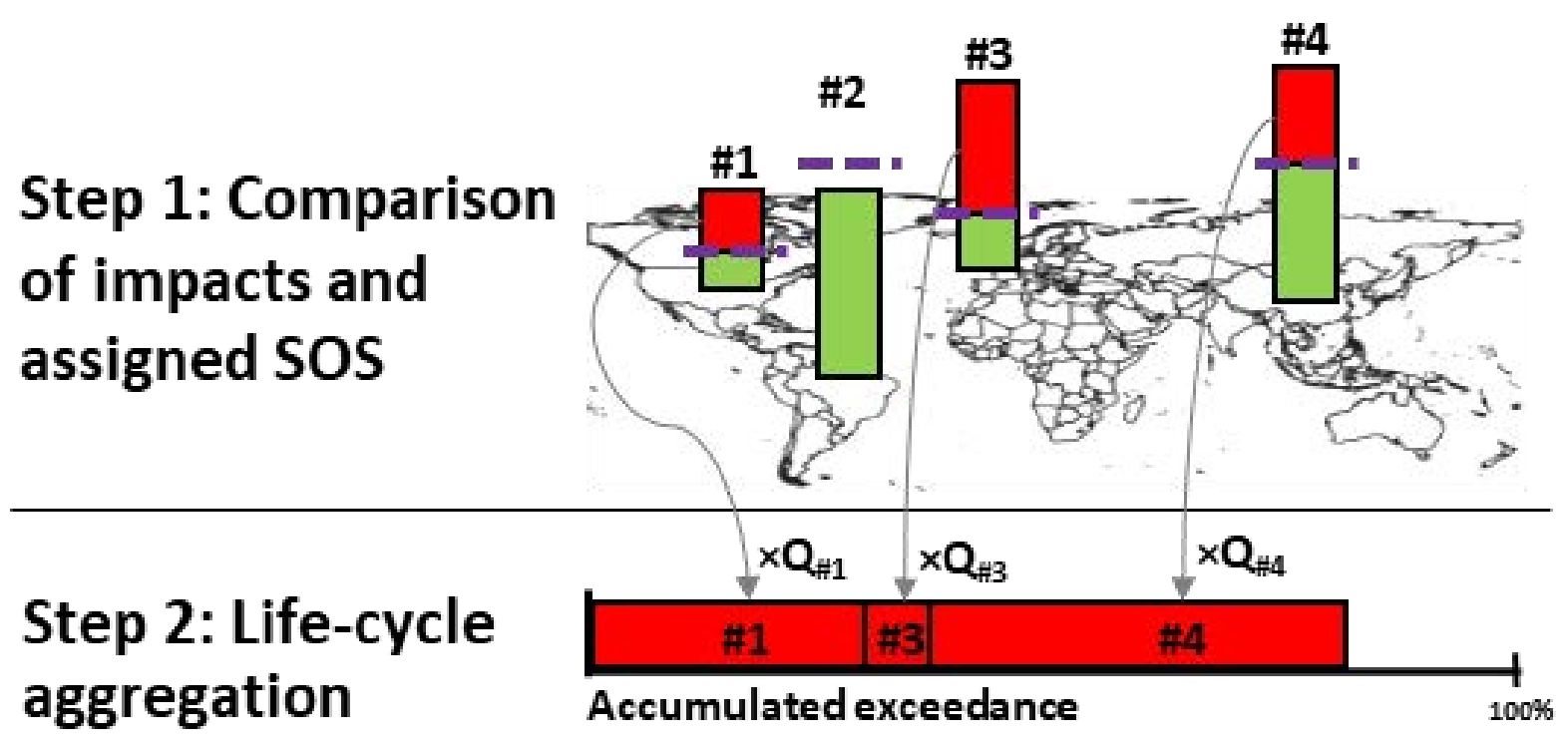

\section{$=$ " SOS assigned to process \\ Q Quantity of reference flow \\ Environmental impact above assigned SOS}

Figure 2: Graphical representation of the two steps involved in the extended process-level approach for a given impact indicator, involving four processes (numbered \#1 to \#4).

\subsubsection{Step 1: Calculation of the occupation of assigned safe operating space}

The first assessment step calculates an occupation of assigned SOS (occ.aSOS) for each process ( $x$ ) and impact indicator ( $k$ ), across a comprehensive set of regional and global PB impact categories. Occ.aSOS is defined as the process' environmental impact (EI - columns in top of Figure 2) divided by the SOS assigned to the process (aSOS - dotted lines in top of Figure 2):

occ. $\operatorname{aSOS}_{\mathrm{x}, \mathrm{j}, \mathrm{k}, \mathrm{s}}=\frac{\mathrm{EI}_{\mathrm{x}, \mathrm{j}, \mathrm{k}}}{\operatorname{aSOS}_{\mathrm{x}, \mathrm{j}, \mathrm{k}, \mathrm{s}}}=\frac{\sum_{\mathrm{e}} \mathrm{CF}_{\mathrm{e}, \mathrm{i}, \mathrm{j}, \mathrm{k}} \times \mathrm{M}_{\mathrm{x}, \mathrm{e}}}{\operatorname{aSOS}_{\mathrm{x}, \mathrm{j}, \mathrm{k}, \mathrm{s}}}$

154 For global impact categories, the calculation of occ.aSOS refers to a single global SOS for all life-cycle 155 processes. For regional impact categories, occ.aSOS refers to the SOS of the specific spatial unit (j) 
Bjørn, A., Sim, S., King, H., Patouillard, L., Margni, M., Hauschild, M. Z., \& Ryberg, M. (2020). Life cycle assessment applying planetary and regional boundaries to the process level: a model case study. (1)

impacted by each process. In many cases, the impacted spatial unit is the same as the spatial unit in which a process is located $(i)$. However, a process may impact several spatial units (for example, due to substance fate processes), in which case occ.aSOS ideally should be calculated for each of them. In all cases, occ.aSOS may be calculated according to different sharing principles for assigning SOS (s), see Section 2.3.4 for a case study application.

The environmental impact (EI) of Eq. 1 is calculated following standard LCA practice by summing the product of CF (developed specifically for PB-LCA) and elementary flow mass (M) over all elementary 164 flows (e). Note that M should correspond to one unit of reference flow of the process (e.g. $1 \mathrm{~kg}$ of crude

The second assessment step calculates the accumulated exceedance of assigned SOS (AE.aSOS) within a illustrated in Figure 2:

$A E \cdot \operatorname{aSOS}_{\mathrm{k}, \mathrm{s}}=\frac{\sum_{x} \sum_{\mathrm{j}}\left(\begin{array}{c}\left(\mathrm{EI}_{\mathrm{x}, \mathrm{j}, \mathrm{k}}-\operatorname{aSOS}_{\mathrm{x}, \mathrm{j}, \mathrm{k}, \mathrm{s}}\right) \times \mathrm{Q}_{\mathrm{x}}, \text { for }_{\mathrm{EI}}, \mathrm{j}, \mathrm{k} \\ \left.0, \operatorname{aSOS}_{\mathrm{x}, \mathrm{j}, \mathrm{k}, \mathrm{s}}\right)\end{array}\right)}{\sum_{x} \sum_{\mathrm{j}}\left(\mathrm{EI}_{\mathrm{x}, \mathrm{j}, \mathrm{k}} \times \mathrm{Q}_{\mathrm{x}}\right)}$

177 column in top of Figure 2 ) across all life-cycle processes $(x)$ and impacted spatial units $(j$, in the case of 178 regional impacts). By contrast, environmental impacts that do not exceed assigned SOS (e.g., for Process 
Bjørn, A., Sim, S., King, H., Patouillard, L., Margni, M., Hauschild, M. Z., \& Ryberg, M. (2020). Life cycle assessment applying planetary and regional boundaries to the process level: a model case study.

$\# 2$ in Figure 2) are left out of the aggregation. These summed environmental impact parts are scaled to the functional unit of a product system by multiplication with the quantity of required reference flow (Q) of each process $(x)$. The denominator in Eq. 2 calculates the life-cycle impact and serves to normalize the accumulated exceedance to a scale of $0 \%$ to $100 \%$ of life-cycle impact (note that an AE.aSOS of $100 \%$ is unlikely, as it would mean zero assigned SOS to all processes). This creates a common scale for all impact indicators $(k)$.

The scaling by $Q$ in Eq. 2 provides additional insights on which of the, potentially large number, of lifecycle processes with occ.aSOS > 1 (identified in Step 1) are driving the part of the life-cycle impact judged to be environmentally unsustainable. In the illustrative example of Figure 2, Process \#3 has the highest occ.aSOS, but not the highest contribution to AE.aSOS, since its reference flow (Q) is only required in a modest amount by the functional unit compared to those of Process \#1 and \#4. The processes that have a high contribution to AE.aSOS can be considered "PB hotspots" and their identification may help inform decisions about where in a life cycle to focus impact reduction efforts most urgently.

\subsection{Spatial aggregation of geographically resolved CFs and SOS}

This section presents an approach to aggregate the CFs and SOS of geographically resolved methods for application within the process-level approach presented above.

\subsubsection{Presentation of aggregation approach}

We propose an aggregation of CFs and SOS at the spatial unit resolution to three spatial resolutions commonly encountered in LCls (Mutel et al., 2019; Patouillard et al., 2018): 1) country, 2) continent and 3) global. The CF aggregation approach is inspired by the approach and nomenclature of Bulle et al. (2019) and Figure 3 provides an illustration: 


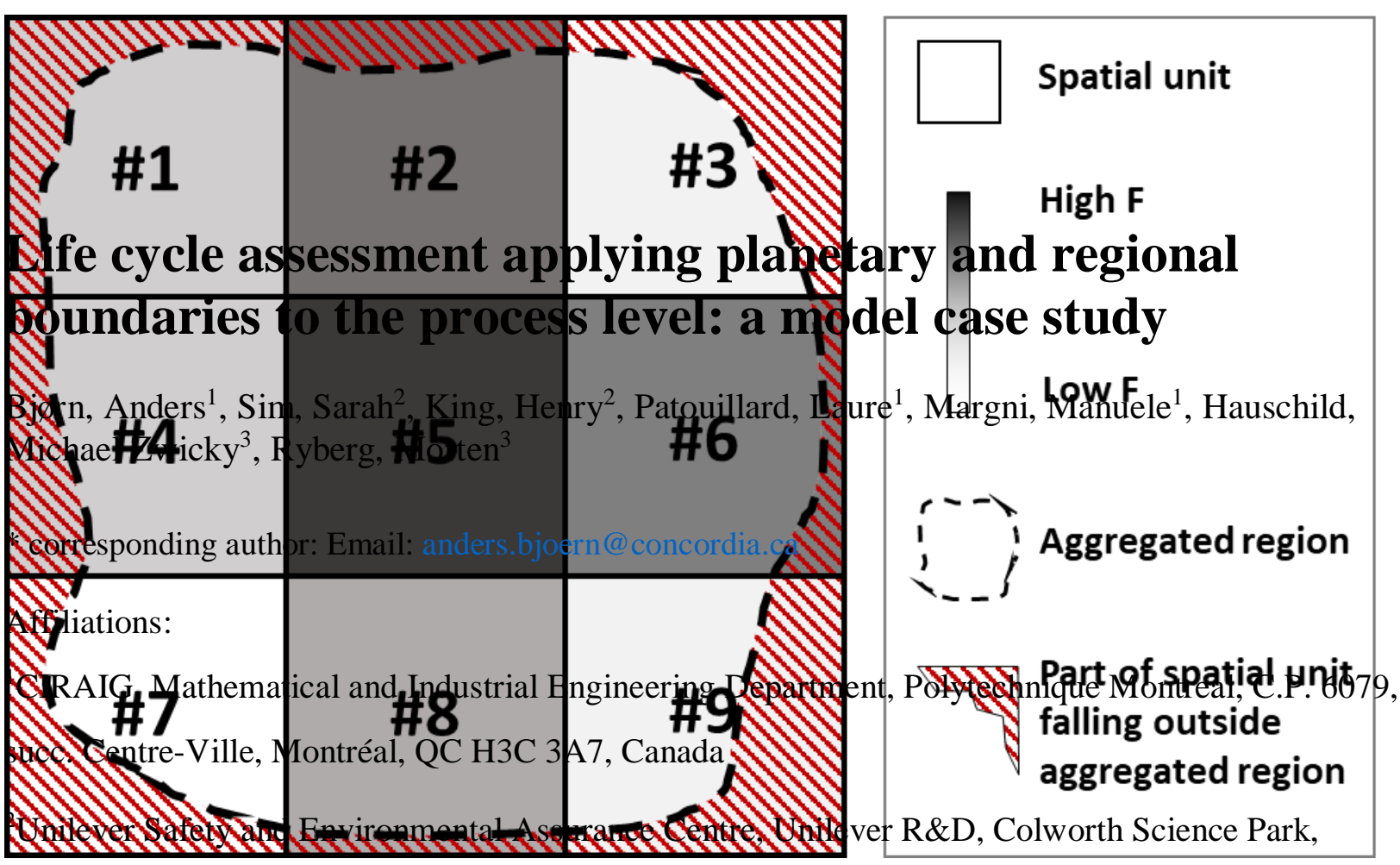

Sharnbrook, MK44 1LQ, UK.

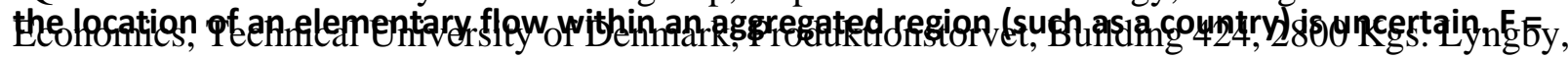

Denmark.

206 total annual quantity of an elementary flow within a spatial unit.

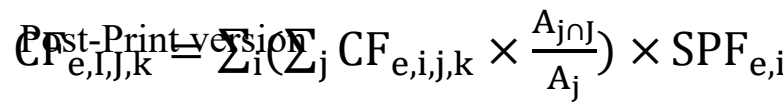

$\mathrm{SPF}_{\mathrm{e}, \mathrm{i}}=\frac{\mathrm{F}_{\mathrm{e}, \mathrm{i}} \times \frac{\mathrm{A}_{\mathrm{i} \cap \mathrm{I}}}{\mathrm{A}_{\mathrm{i}}}}{\sum_{\mathrm{i}} \mathrm{F}_{\mathrm{e}, \mathrm{i}} \times \frac{\mathrm{A}_{\mathrm{i} \cap \mathrm{I}}}{A_{\mathrm{i}}}}=\frac{\mathrm{F}_{\mathrm{e}, \mathrm{i}} \times \frac{\mathrm{A}_{\mathrm{i} \cap \mathrm{I}}}{\mathrm{A}_{\mathrm{i}}}}{\mathrm{F}_{\mathrm{e}, \mathrm{I}}}$

Eq. 3 and 4 can be used to transform a set of spatial unit CFs to a single CF for an aggregated region (e.g.

212 a country) in which an elementary flow is known to occur. In cases where an elementary flow impacts

213 several spatial units (e.g., due to atmospheric transport and deposition) Eq. 3 and 4 can be used to

214 calculate a set of aggregated CFs, accounting for all impacted aggregated regions $(\mathrm{J})$. The inner 
Bjørn, A., Sim, S., King, H., Patouillard, L., Margni, M., Hauschild, M. Z., \& Ryberg, M. (2020). Life cycle assessment applying planetary and regional boundaries to the process level: a model case study.

summation of Eq. 3 adds CFs for all impacted spatial units $(j-$ e.g., the nine spatial units in the example

of Figure 3) that fall within the impacted aggregated region of interest $(J)$. The area fraction within the

inner summation downscales each of these CFs when the impacted spatial unit partially falls outside the

Life cycle assessment applying planetary and regional and and ants boundaries to the process level: a model case study

219 in the example of Figure 3, except \#5.

Bjørn, Anders ${ }^{1}$, Sim, Sarah ${ }^{2}$, King, Henry ${ }^{2}$, Patouillard, Laure ${ }^{1}$, Margni, Manuele ${ }^{1}$, Hauschild, 220 Michael Zwicky ${ }^{3}$, Ryberg, Morten ${ }^{3}$

221 The outer summation of Eq. 3 calculates an average of the CFs of all spatial units (i) that fall within the * corresponding author: Email: anders.bjoern@concordia.ca

222 aggregated region in which the elementary flow occurs $(I)$, weighted by the spatial proportionality factor Affiliations:

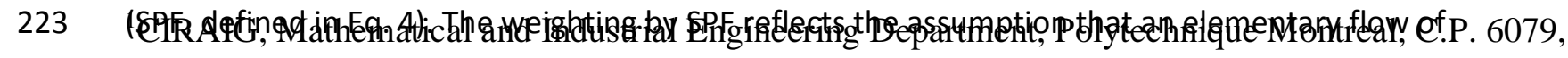

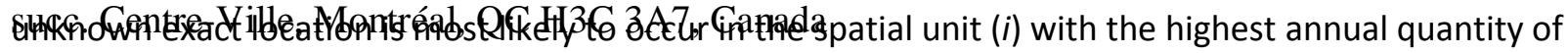

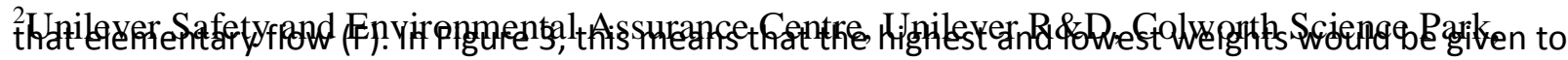
Sharnbrook, MK44 1LQ, UK.

226 the CFs for spatial unit \#5 and \#7, respectively. The area fraction in Eq. 4 serves to downscale these ${ }^{3}$ Quantitative Sustainability Assessment group, Department of Technology, Management and

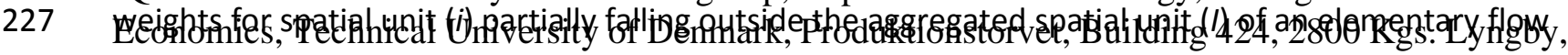
Pagain, this is the case for eight of the nine spatial unit in the example of Figure 3). The weighting by SPF 229 in CF aggregation is common in regionalized LCIA methods and is recommended by the UNEP-SETAC Life 230 GxGSE-PritiativersYOFking group on the harmonization of LCIA regionalization (Mutel et al., 2019). The 231 main difference between those recommendations and the CF aggregation approach proposed here is 232 that conventional LCA aggregates impacts globally, whereas PB-LCA is concerned with specific impacted 233 aggregated regions (such as countries).

235 Next, an SOS for all impacted aggregated regions $(J)$ is calculated by summing the SOS of all the 236 impacted spatial units (j) falling within each J (again, downscaling where needed):

$237 \operatorname{SOS}_{\mathrm{J}, \mathrm{k}}=\sum_{\mathrm{j}}\left(\operatorname{SOS}_{\mathrm{j}, \mathrm{k}} \times \frac{\mathrm{A}_{\mathrm{j} \cap \mathrm{J}}}{\mathrm{A}_{\mathrm{j}}}\right)$ 
Bjørn, A., Sim, S., King, H., Patouillard, L., Margni, M., Hauschild, M. Z., \& Ryberg, M. (2020). Life cycle assessment applying planetary and regional boundaries to the process level: a model case study. The International Journal of Life Cycle Assessment, 25(11), 2241-2254. https://doi.org/10.1007/s11367-020-01823-8

Aggregated CFs and SOS can be used to calculate occ.aSOS and AE.aSOS according to Eq. 1 and 2, with $i$ replaced by $I$ and $j$ replaced by $J$.

\section{Life cy.cle apsssessment applving planetary and regional boundaries to the process level: a model case study flows}

Bjørn, Anders ${ }^{1}$, Sim, Sarah ${ }^{2}$, King, Henry ${ }^{2}$, Patouillard, Laure ${ }^{1}$, Margni, Manuele ${ }^{1}$, Hauschild,

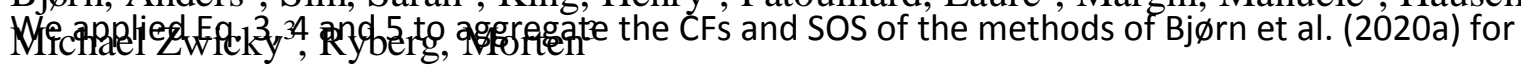

Freshwater use and Bjørn et al. (2020b) for the nitrogen part of Biogeochemical flows using geographic * corresponding author: Email: anders.bjoern@concordia.ca

information systems (GIS) software with a Python code. Supplementary Material (SM) 1 presents Affiliations:

rethaq

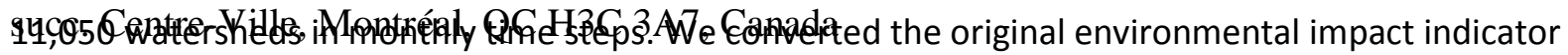

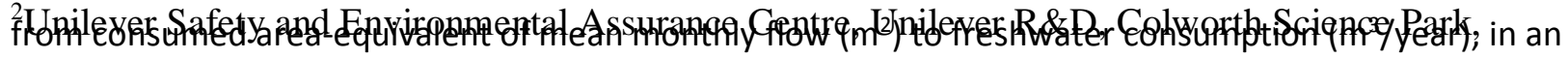

Sharnbrook, MK44 1LQ, UK.

effort to make the aggregation of process-level PB-LCA results (see Section 2.1.2) easier to interpret. We ${ }^{3}$ Quantitative Sustainability Assessment group, Department of Technology, Management and

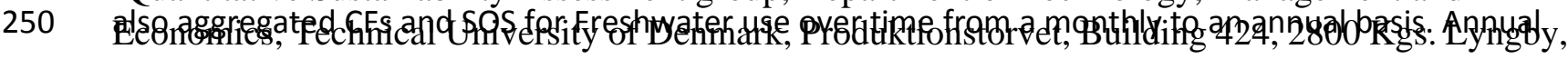

Denmark.

251 factors are not able to capture seasonal variations, but more practical to apply than monthly, due to the 252 current lack of temporal information in most $\mathrm{LCl}$ databases.

\section{Post-Print version}

254 The method for the nitrogen part of Biogeochemical flows of Bjørn et al. (2020c) provides SOS for 3,797 255 grid cells (each with an area of $\approx 60,000 \mathrm{~km}^{2}$ at the Equator) for natural soil, SOS for 6,081 watersheds for 256 freshwater and SOS for 66 large marine ecosystems for coastal water and corresponding CFs for 257 different chemical forms of nitrogen emissions to soil, freshwater, coastal water and air. We aggregated 258 the CFs and SOS for impacts on natural soil and freshwater and left out the variables related to coastal 259 water, as we judged the method's spatial resolution of coastal water to be too crude to quantify impacts 260 on that environmental compartment. 
Bjørn, A., Sim, S., King, H., Patouillard, L., Margni, M., Hauschild, M. Z., \& Ryberg, M. (2020). Life cycle assessment applying planetary and regional boundaries to the process level: a model case study.

2.3. Case study application of process-level PB-LCA

\subsubsection{Goal and scope}

264 We based the cradle-to-grave PB-LCA case study on a model European laundry detergent as described by Ryberg et al. (2018b). We adapted the case study of Ryberg et al. (2018b) for the application of geographically resolved PB-LCA methods (see SM 2 for details). We defined the functional unit as "doing 196 washes per year of $4.5 \mathrm{~kg}$ of normally soiled dry fabric at $40.4^{\circ} \mathrm{C}$ with a model liquid detergent in the $U K^{\prime \prime}$. The washing frequency, load and temperature is representative of the user behaviour in the average household in UK and Ireland in the year 2014, according to the International Association for

Soaps, Detergents and Maintenance Products (AISE, 2015a). The water use and detergent dosage per washing cycle were based on pan-European technical standards for washing machines (AISE, 2015b). We

272 followed attributional modelling principles (as prescribed by Ryberg et al. (2018a) for this type of 273 assessment) and handled multifunctional processes by economic allocation. SM 8 contains a reflection 274 on the methodological choices of the case study.

\section{$275 \quad$ 2.3.2. LCl modelling}

276 We modified the inventory of Ryberg et al. (2018b) as a basis for the LCI modelling executed in SimaPro 277 V8.5.2.0 (PRé, 2019). This involved changing all flow quantities (product flows and elementary flows) to 278 match the household-scale functional unit of this case study and replacing European average processes 279 with UK-specific processes in the detergent manufacture, use and waste treatment stages (e.g., related 280 to electricity grid mix) (see details in SM 2).

282 Next, we selected a subset of all processes involved in the full inventory $(>1,000)$ for the process-level 283 PB-LCA. This was done to keep a focus on processes in the foreground system and on processes in the 284 background system that have a non-negligible contribution to global impacts, as well as to keep the 285 number of calculations manageable. Hence, we selected the following processes: 1) all foreground 
Bjørn, A., Sim, S., King, H., Patouillard, L., Margni, M., Hauschild, M. Z., \& Ryberg, M. (2020). Life cycle assessment applying planetary and regional boundaries to the process level: a model case study.

processes related to ingredients, and 2 ) all processes that contributed more than $1 \%$ to any global

impact for the impact indicators of Ryberg et al. (2018a). This resulted in the selection of 61 processes, see Figure 4, which accounted for, on average, $88 \%$ of the life-cycle impacts for the nine impact Life cycle assessment applying planetary and regional
boutcandaries to the process level: a model case study

Bjørn, Anders ${ }^{1}$, Sim, Sarah ${ }^{2}$, King, Henry ${ }^{2}$, Patouillard, Laure ${ }^{1}$, Margni, Manuele ${ }^{1}$, Hauschild, AGilEhael Zwicky|, RyB
* corresponding author:
Affitiations: Eitg(1)Morten ${ }^{3}$ Ingredients and packaging

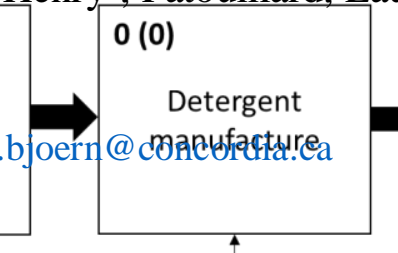
Emailifactures.bjoern@mankufatturea

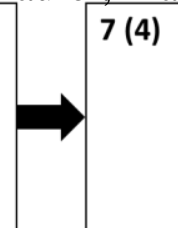

${ }^{1}$ CIRAIG, Mathematica $\mathbf{3}(\mathbf{0}) \quad 30(0)$ sucẹrecentrtpiçalsillé, Montréal, QC H3C 3A7, Canada Energy and infrastructure

${ }^{2}$ Unilever Safety and Environmental Assurance Centre, Unilever R\&D, Colworth Science Park, Figure 4: Schematic representation of the product system organized into seven major clusters of Sharnbrook, MK44 1LQ, UK.

processes. The number of processes that were selected for process-level assessment (61 in total) are ${ }^{3}$ Quantitative Sustainability Assessment group, Department of Technology, Management and

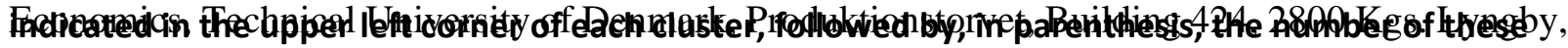
Denmark. processes that were spatialized ( 20 in total).

Pext-Printarion the two geographically resolved methods described in Section 2.2.2, we divided the 61 processes into two groups, one to be spatialized, that is, assigned to a spatial unit or aggregated region (Patouillard et al., 2018), and another group to remain spatially generic. The spatially generic group was composed of the 41 background processes that contributed less than $1 \%$ to global impacts for Freshwater use and the nitrogen part of Biogeochemical flows according to the impact indicators of Ryberg et al. (2018a). We judged spatialization to be unnecessary for these processes, due to their low contribution to the two impact categories for which geographically resolved PB-LCA methods exist (Bjørn et al., 2020c, 2020b). The remaining 20 processes to be spatialized (see parentheses of Figure 4) were part of the foreground system and/or contributed more than $1 \%$ to global impacts for Freshwater 
Bjørn, A., Sim, S., King, H., Patouillard, L., Margni, M., Hauschild, M. Z., \& Ryberg, M. (2020). Life cycle assessment applying planetary and regional boundaries to the process level: a model case study.

use and the nitrogen part of Biogeochemical flows. We based their spatialization on representative

locations of production (e.g. a specific manufacturing facility), or on geographically resolved production statistics (see Section 4.4.2 for uncertainties related to spatialization). For example, we spatialized the

\section{Life pycle assessment applying planetary and regional} boundaries to the process level: a model case study

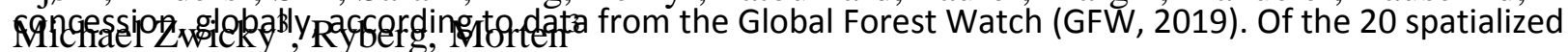
processes, we attributed 13 to a spatial unit (e.g., a specific watershed or grid-cell) and 7 to a country.
$*$ corresponding author: Email: anders.bjoern@concordia.ca

Note that amongst the 61 processes selected for process-level assessment, we constructed 12 by Affiliations:

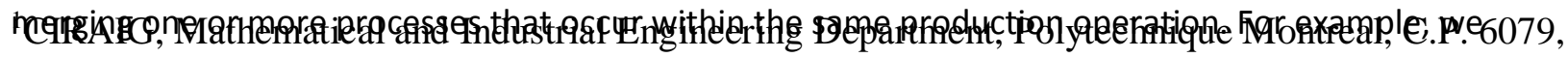

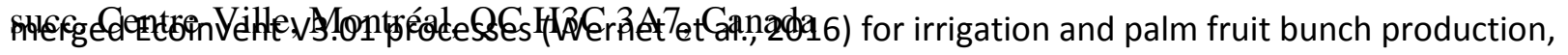

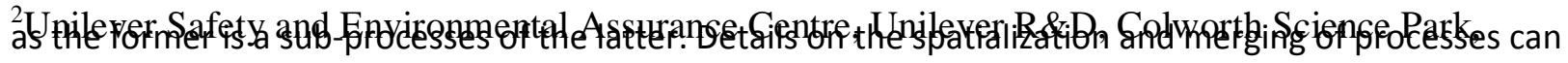
Sharnbrook, MK44 1LQ, UK. be found in SM 3.

${ }^{3}$ Quantitative Sustainability Assessment group, Department of Technology, Management and Economics, Technical University of Denmark, Produktionstorvet, Building 424, 2800 Kgs. Lyngby, Denmark

We applied the PB-LCA methods of Bjørn et al. (2020b) (for Freshwater use) and Bjørn et al. (2020c) (for thespifragen pasioff Biogeochemical flows), including the aggregated CFs and SOS (see Section 2.2), as well as Ryberg et al. (2018a) (for a comprehensive set of impact categories) to each of the 61 selected processes. For each process, we matched its spatialization with a specific spatial unit or aggregated region. For example, we applied CFs aggregated to the country level to processes spatialized to countries and global CFs to the 41 spatially generic processes. For the spatially generic impact categories of Ryberg et al. (2018a) we applied global CFs to all 61 processes, whether spatialized or not. Note that the global CFs and SOS of Bjørn et al. (2020b) and Bjørn et al. (2020c) for Freshwater use and the nitrogen part of Biogeochemical flows are not identical to the global CFs and SOS of Ryberg et al. (2018a) for those two impact categories. This is because the former reflects an aggregation of regional 
Bjørn, A., Sim, S., King, H., Patouillard, L., Margni, M., Hauschild, M. Z., \& Ryberg, M. (2020). Life cycle assessment applying planetary and regional boundaries to the process level: a model case study.

boundaries and the latter directly reflects the PBs estimated in Steffen et al. (2015) and because of differences in impact indicators (more details in Section 4.2). The method for the nitrogen part of Biogeochemical flows of Bjørn et al. (2020c) is the only case where an elementary flow impacts more

atmospheric transport and deposition of air emissions. We applied that method to calculate

Bjørn, Anders ${ }^{1}$, Sim, Sarah ${ }^{2}$, King, Henry ${ }^{2}$, Patouillard, Laure ${ }^{1}$, Margni, Manuele ${ }^{1}$, Hauschild,

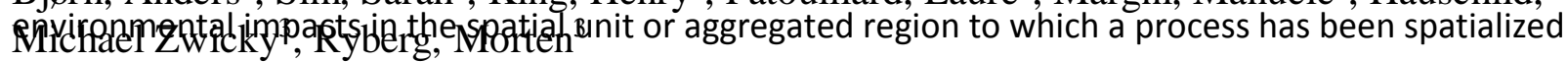

336 (i.e., using CFs where $i=j$ in Eq. 1 or $I=J$ in Eq. 3). In addition, we calculated the global impact of each * corresponding author: Email: anders.bjoern@concordia.ca process by summing the calculated impacts for each spatial unit $(j)$ or region $(J)$, globally.
Affiliations:

${ }^{1}$ CIRAIG, Mathematical and Industrial Engineering Department, Polytechnique Montreal, C.P. 6079,

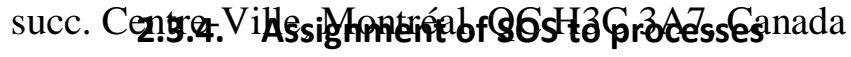

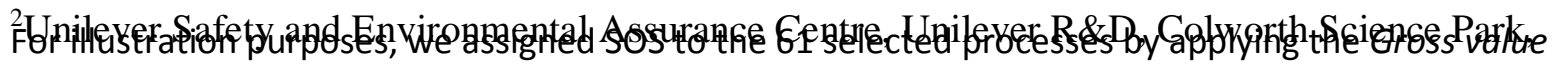

Sharnbrook, MK441LQ, UK.

added (GVA) principle, modified to account for emission transport across regions. A region is, in this ${ }^{3}$ Quantitative Sustainability Assessment group, Department of Technology, Management and

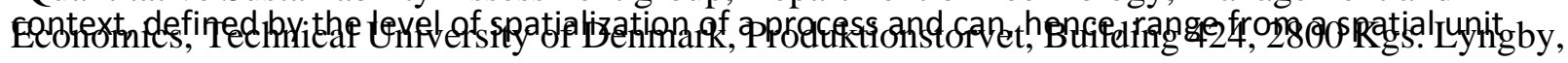

Penmark.

(watershèds or grid-cells) to the global level. For the sake of simplicity, we only assigned regional SOS to a process for the region in which the process is situated. The GVA principle is one of the most commonly 4test-iprthe vitersthre (Bjørn et al., 2020a). GVA can be defined as revenue generated by a process minus the cost of purchased goods and services and is largely composed of salary to employees and operating surplus (Eurostat, 2008; Randers, 2012). The principle reflects the perspective that the regional SOS assigned to a production process should be proportional to its contribution to the regional economy. We calculated the assigned regional SOS (aSOS) to a process $(x)$ for a given impact indicator $(k)$ as:

$$
\operatorname{aSOS}_{x, k}=\frac{G V A_{x}}{G V A_{\text {total }}} \times S O S_{k} \times \frac{E I_{\text {endogenous }, k}}{E I_{\text {total }, k}}=\frac{P_{x} \times r G V A_{x}}{G V A_{\text {total }}} \times S O S_{k} \times \frac{E I_{\text {endogenous }, k}}{E I_{\text {endogenous }, k}+E I_{\text {exogenous }, k}} \text { (Eq. 6) }
$$

$\mathrm{GVA}_{x}$ is the GVA of process $x$ and GVA total is the total GVA of the region in which $x$ is situated. $P$ is the basic price (in short, the price at the "factory gate" before taxes and subsidies are considered (Eurostat, 
Bjørn, A., Sim, S., King, H., Patouillard, L., Margni, M., Hauschild, M. Z., \& Ryberg, M. (2020). Life cycle assessment applying planetary and regional boundaries to the process level: a model case study.

2008)) of a unit of product flow (e.g., $1 \mathrm{~kg}$ palm oil) and rGVA is the relative GVA (expressed as GVA per unit of basic price). GVA total was calculated using a highly geographically resolved global dataset of gross domestic product (Kummu et al., 2018). P was obtained from Ecoinvent 3.5 (Wernet et al., 2016) and Ifife cycle assessment applying planetary and regional boundaries to the process level: a model case study classification of Ecoinvent processes to Exiobase product categories of Agez et al. (2020). SOS was Bjørn, Anders ${ }^{1}$, Sim, Sarah ${ }^{2}$, King, Henry ${ }^{2}$, Patouillard, Laure ${ }^{1}$, Margni, Manuele ${ }^{1}$, Hauschild,

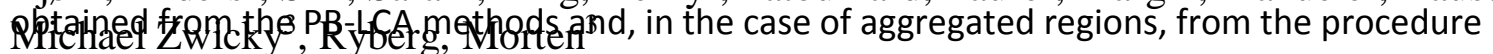

presented in Section 2.2.

* corresponding author: Email: anders.bjoern@concordia.ca

Affiliations:

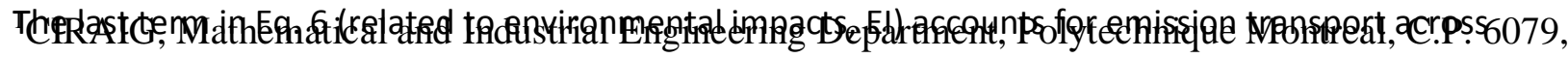

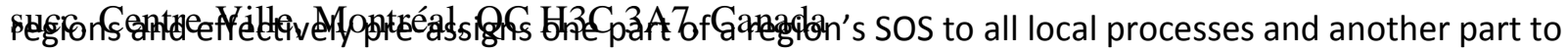

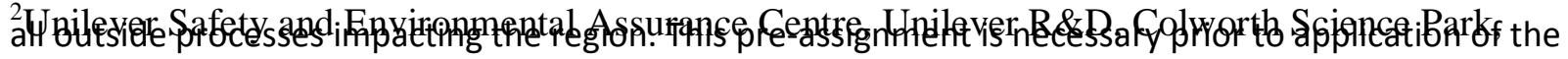
Sharnbrook, MK44 1LQ, UK.

GVA principle, because processes located outside a region do not directly contribute to the economy of ${ }^{3}$ Quantitative Sustainability Assessment group, Department of Technology, Management and

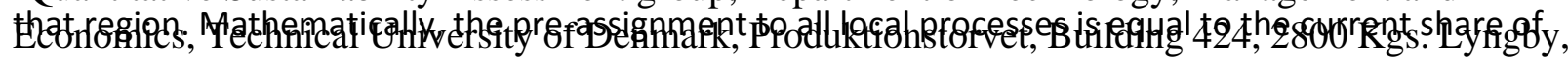

Denmark.

the total impact on a region that is endogenous, as opposed to exogenous (this is in accordance with the

Status Quo sharing principle (Ryberg et al., 2018b)). We quantified El endogenous and El exogenous by

qharapterizingrgeographically resolved inventories of total elementary flows (also used as $F$ in the

application of Eq. 4, see SM 1 for data sources). The pre-assigned share of SOS to a region's local

processes ('El $\left.\right|_{\text {endogenous }} /\left(\mathrm{El}_{\text {endogenous }}+\mathrm{El}_{\text {exogenous }}\right)$ ' in Eq. 6) is 1 for most impact categories considered here.

This is because global impact categories (per definition) only have a single region and because impacts

for some regional impact categories (like Freshwater use) are limited to the region of the elementary

flow (meaning zero exogenous impacts). However, for the nitrogen part of Biogeochemical flows of

Bjørn et al. (2020c) emissions of nitrogen from outside a region can impact the region through

atmospheric transport and deposition of air emissions and through riverine transport of freshwater and soil emissions. For that impact category, we found the pre-assigned share of SOS to a region's local 
Bjørn, A., Sim, S., King, H., Patouillard, L., Margni, M., Hauschild, M. Z., \& Ryberg, M. (2020). Life cycle assessment applying planetary and regional boundaries to the process level: a model case study.

380

processes often to be less than half and that it decreases with decreasing region size. SM 4 contains details on the aSOS calculations.

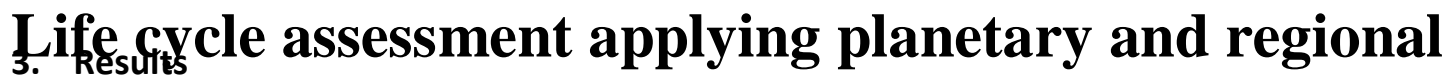 boundaries to the process level: a model case study}

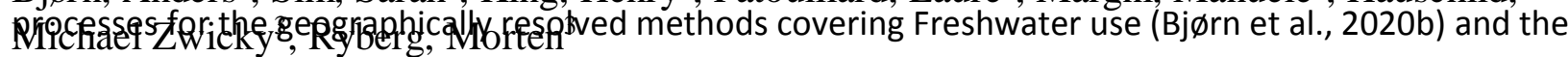

nitrogen part of Biogeochemical flows (Bjørn et al., 2020c). Results are also given for the same two * corresponding author: Email: anders.bjoern@concordia.ca

impact categories in the method of Ryberg et al. (2018a), which are spatially generic (nitrogen) and Affiliations:

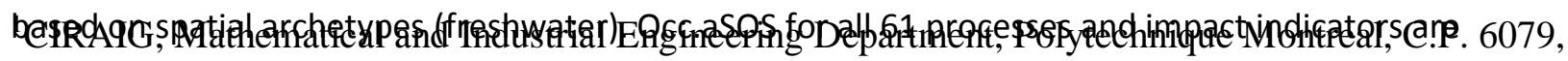

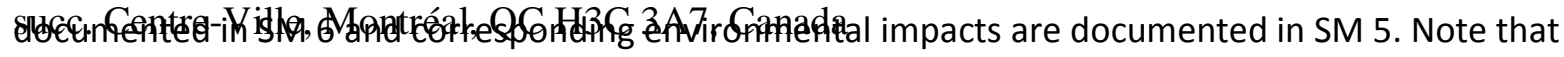

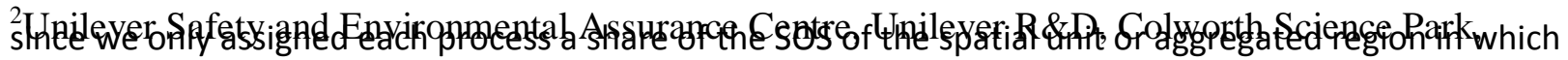

Sharnbrook, MK44 1LQ, UK.

it is situated, only a single occ.aSOS was calculated for each process and impact indicator. For an

${ }^{3}$ Quantitative Sustainability Assessment group, Department of Technology, Management and examblhief, a PB-chffic ay

Denmark.

391 see the càse study of Bjørn et al. (2020c). Processes with occ.aSOS above 1 have higher impacts than

392 their assigned SOS, with respect to the GVA sharing principle, thus indicating potential environmental

393 yostspainabilityiołote that such processes do not necessarily have a high contribution to life-cycle

394 impacts, because occ.aSOS is independent of the functional unit here (see Section 2.1.1). 
Bjørn, A., Sim, S., King, H., Patouillard, L., Margni, M., Hauschild, M. Z., \& Ryberg, M. (2020). Life cycle assessment applying planetary and regional boundaries to the process level: a model case study.

The International Journal of Life Cycle Assessment, 25(11), 2241-2254. https://doi.org/10.1007/s11367-020-01823-8

Table 2: Occupation of assigned SOS (dimensionless) by the 20 spatially resolved processes for Freshwater use and the nitrogen part of

Biogeochemical flows. Results for all processes and impact indicators are given in SM 6. Values above 1 illustrate exceedance of assigned SOS

and are shown in bold. Processes in italic are spatialized to a country instead of a spatial unit.

\section{Life cycle assessment applying planetary and regional boundaries to the process level: a model case study}

Bjørn, Anders ${ }^{1}$, Sim, Sarah ${ }^{2}$, King, Henry², Patouillard, Laure ${ }^{1}$, Margni, Manuele ${ }^{1}$, Hauschild,

Michael Zwicky³, Ryberg, Morten ${ }^{3}$

Biogeochemical

Biogeochemical flows,

flows, nitrogen

nitrogen (natural soil)

* corresponding author: Email: anders.bjgern@concordia.ca

(freshwater) (Bjørn (Bjørn et al., 2020c)

Affiliations:

Freshwater use

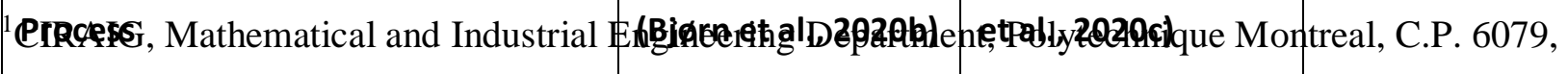

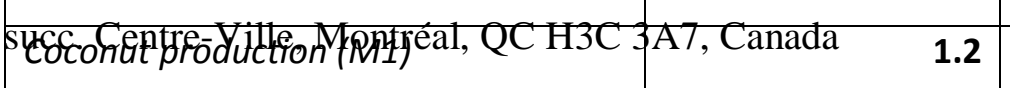

0.015

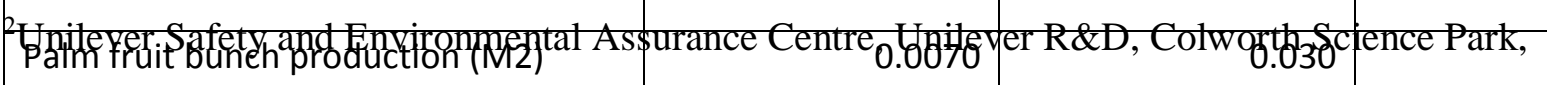

Sharnbrook, MK44 1LQ, UK.

Palm fruit bunch production, on land

${ }^{3}$ Quantitative Sustainability Assessment group, Department of Technology, Managenent and

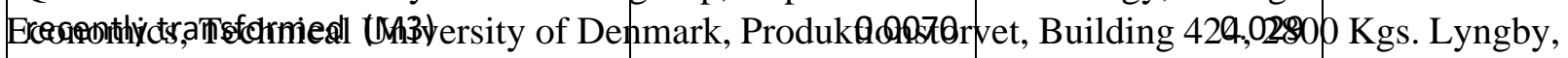

Denmark.

\begin{tabular}{|l|}
\hline Denmark. \\
\hline Rapeseed, extensive production (M4) \\
\hline Rapeseed, intensive production (M5) \\
\hline PAacteradoddprsidunction (I1) \\
\hline Anionic surfactant production (I2) \\
\hline
\end{tabular}

52

521700

0

45

\begin{tabular}{l|l|}
\hline 45 & \\
\hline 20
\end{tabular}

1500

0

\begin{tabular}{r|r}
0 & \\
\hline 0.054 &
\end{tabular}

\section{Differently resolved methods}

\begin{tabular}{|l|l|}
\hline Biogeochemical &
\end{tabular}

$\begin{array}{ll}\text { Freshwater use flows, nitrogen } & \end{array}$

(spatial archetype (spatially generic)

resolution) (Ryberg (Ryberg et al.

et al., 2018a)

2018a) 
Bjørn, A., Sim, S., King, H., Patouillard, L., Margni, M., Hauschild, M. Z., \& Ryberg, M. (2020). Life cycle assessment applying planetary and regional boundaries to the process level: a model case study.

The International Journal of Life Cycle Assessment, 25(11), 2241-2254. https://doi.org/10.1007/s11367-020-01823-8

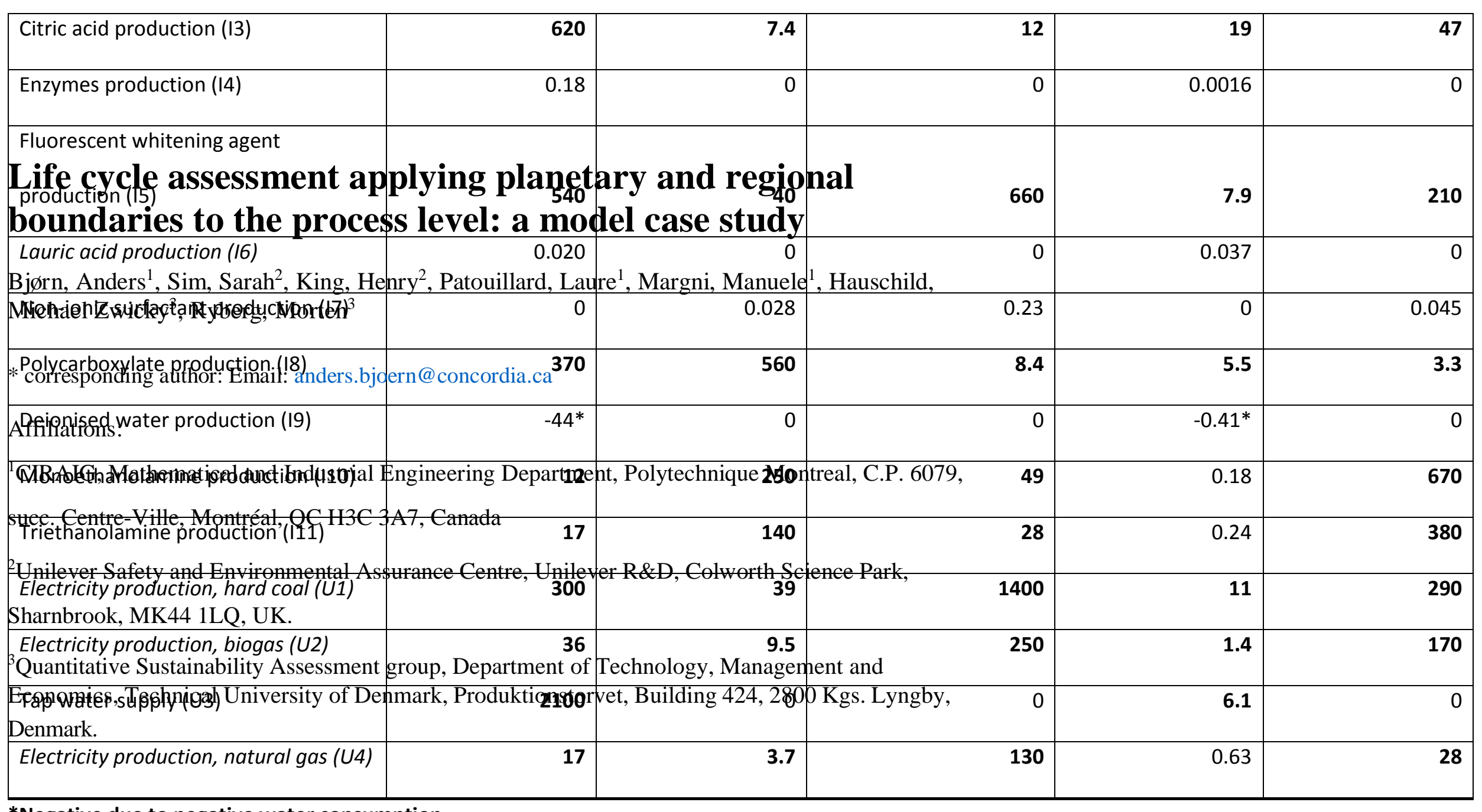

398 *Negative due to negative water consumption.

Post-Print version 
Bjørn, A., Sim, S., King, H., Patouillard, L., Margni, M., Hauschild, M. Z., \& Ryberg, M. (2020). Life cycle assessment applying planetary and regional boundaries to the process level: a model case study.

399 Figure 5 shows the accumulated exceedance of assigned SOS (AE.aSOS) of the 61 processes as defined in

Eq. 2, according to the process clusters of Figure 4. The results are given for 1 ) the three impact indicators covered by the geographically resolved methods for Freshwater use (Bjørn et al., 2020b) and

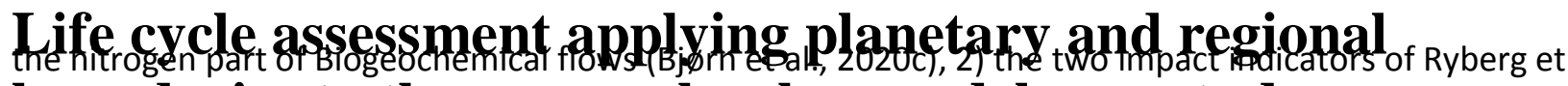 boundaries to the process level: a model case study}

403 al. (2018a) ("differently resolved") covering those impact categories, and 3) the remaining indicators of Bjørn, Anders ${ }^{1}$, Sim, Sarah ${ }^{2}$, King, Henry ${ }^{2}$, Patouillard, Laure ${ }^{1}$, Margni, Manuele ${ }^{1}$, Hauschild,

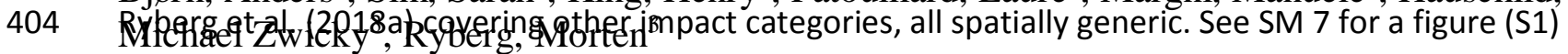

405 with all 61 processes and another figure (S2) with processes categorized according to level of * corresponding author: Email: anders.bjoern@concordia.ca spatialization (spatial unit, country or none). Since AE.aSOS is normalized by the life-cycle impact, for
Affiliations:

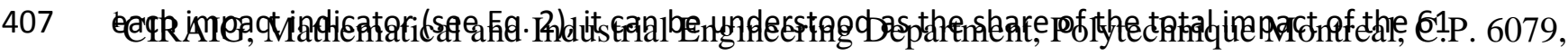

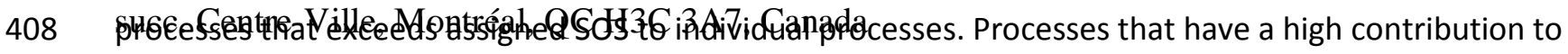

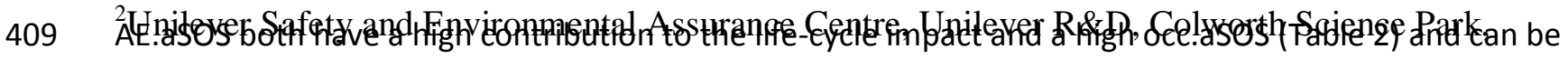
Sharnbrook, MK44 1LQ, UK.

410 considered "PB hotspots".

${ }^{3}$ Quantitative Sustainability Assessment group, Department of Technology, Management and Economics, Technical University of Denmark, Produktionstorvet, Building 424, 2800 Kgs. Lyngby, Denmark.

Post-Print version 
Bjørn, A., Sim, S., King, H., Patouillard, L., Margni, M., Hauschild, M. Z., \& Ryberg, M. (2020). Life cycle assessment applying planetary and regional boundaries to the process level: a model case study.

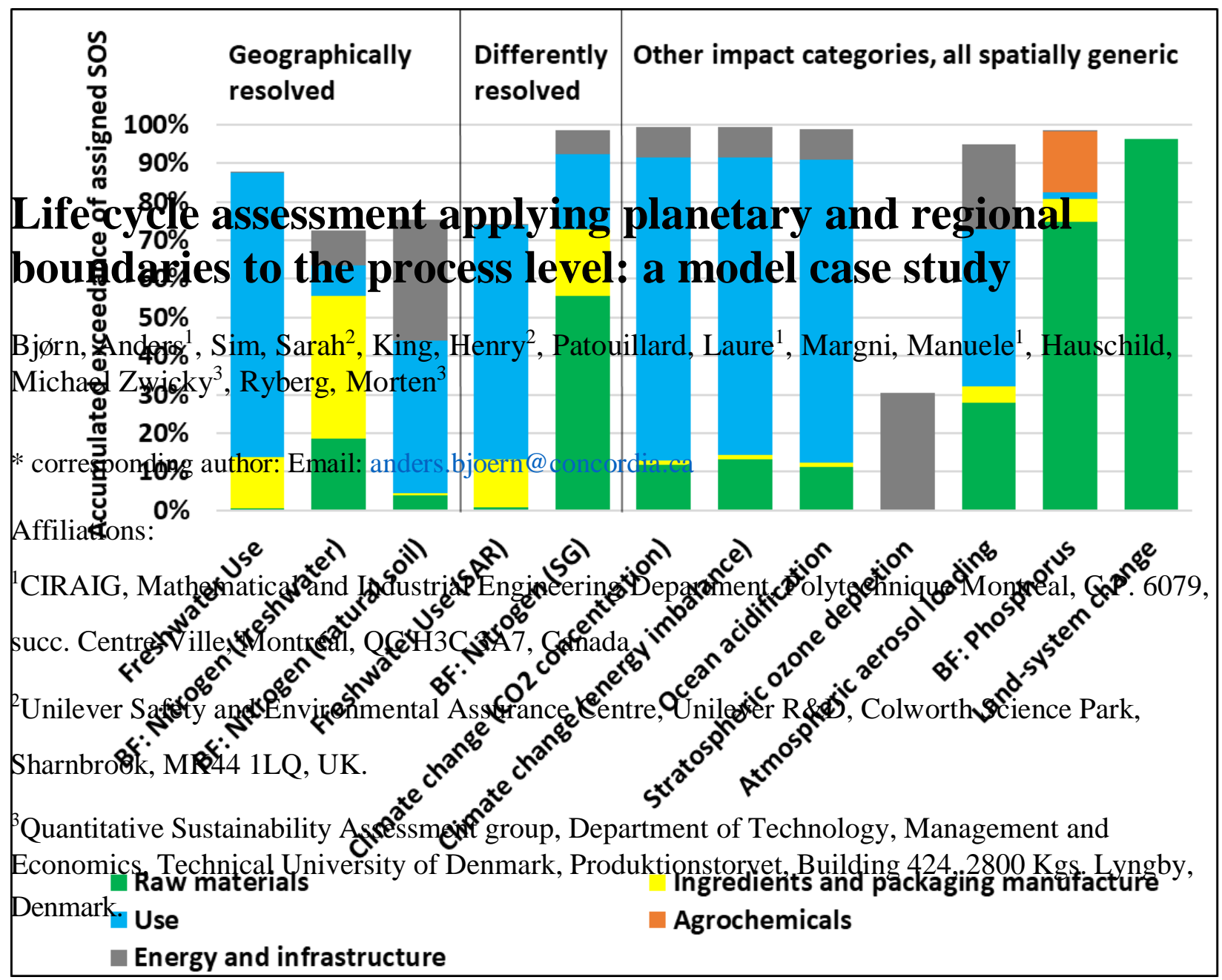

Figure 5: Accumulated exceedance of assigned SOS (normalized by life-cycle impacts) for the 61

Post-Print version

selected case study processes organized in five life cycle stages for 12 PB-LCA impact indicators. BF =

Biogeochemical flows. GR = geographically resolved. $S A R=$ spatial archetype resolution. SG = spatially

\section{Discussion}

4.1. Insights from case study application of geographically resolved methods to a full life cycle

419 The development of the spatially aggregated CFs and SOS (Section 2.2) allowed the occupation of 420 assigned SOS to be calculated for all 61 selected processes for the geographically resolved methods 421 (Bjørn et al., 2020c, 2020b) (column 2-4 of Table 2 and SM 6). Hence, in addition to the 13 processes 
Bjørn, A., Sim, S., King, H., Patouillard, L., Margni, M., Hauschild, M. Z., \& Ryberg, M. (2020). Life cycle assessment applying planetary and regional boundaries to the process level: a model case study.

that could be spatialized to a watershed or a grid cell, the new approach allowed coverage of a further 7 processes spatialized to a country (in italics in Table 2) as well as coverage of 41 spatially generic processes (see SM 6). This expansion of case study processes from 13 to 61 lead to an $18 \%$ and $62 \%$

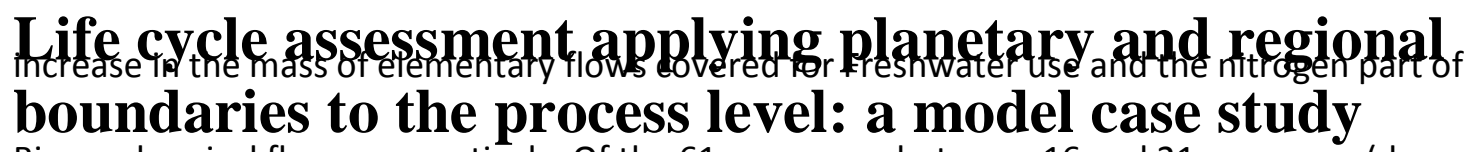
Bjørn, Anders ${ }^{1}$, Sim, Sarah ${ }^{2}$, King, Henry ${ }^{2}$, Patouillard, Laure ${ }^{1}$, Margni, Manuele ${ }^{1}$, Hauschild,

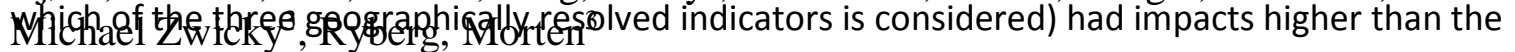

assigned SOS (Bjørn et al., 2020c, 2020b) (see Table 2 and SM 6). Of these 16-21 processes, 5-7 were * corresponding author: Email: anders.bjoern@concordia.ca

spatialized to a spatial unit, 5-6 to a country and 3-10 were spatially generic (again, depending on which Affiliations:

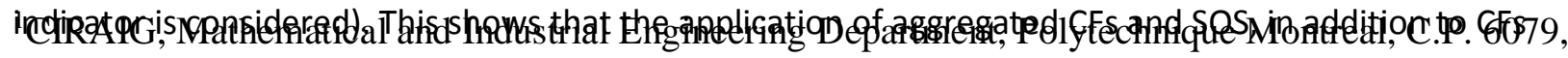

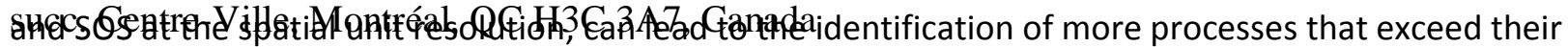

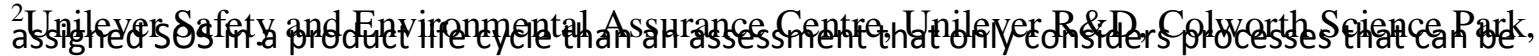

Sharnbrook, MK44 1LQ, UK.

spatialized to a spatial unit.

${ }^{3}$ Quantitative Sustainability Assessment group, Department of Technology, Management and Economics, Technical University of Denmark, Produktionstorvet, Building 424, 2800 Kgs. Lyngby,

Denmark. geographically resolved impact indicators (see Figure 5). For Freshwater use, a single process, tap water subpllpfint the rspontage, spatialized to the Thames basin in the UK, accounted for more than half of AE.aSOS (see Figure S1 in SM 7). This was due to a high environmental impact (a water consumption of $8.1 \mathrm{~m}^{3}$, compared to a life-cycle total of $12.1 \mathrm{~m}^{3}$ ) and a high occ.aSOS (2100, see Table 2 ), according to our application of the GVA principle (the choice of sharing principle in PB-LCA is further discussed in Section 4.4.4). For the two geographically resolved impact indicators related to the nitrogen part of Biogeochemical flows, AE.aSOS was driven by a larger number of processes, with 12 processes each accounting for $5-28 \%$ of exceedance for one or both indicators (see Figure S1 in SM 7). For the indicator related to freshwater impacts of nitrogen emissions, around half of the highly contributing processes related to Ingredients and packaging manufacture and were spatialized to a spatial unit. By comparison, 
Bjørn, A., Sim, S., King, H., Patouillard, L., Margni, M., Hauschild, M. Z., \& Ryberg, M. (2020). Life cycle assessment applying planetary and regional boundaries to the process level: a model case study.

the highly contributing processes for the nitrogen indicator related to natural soil impacts were all part of the Use stage and Energy and infrastructure and were spatialized to a country or were spatially generic (see Figure S2 in SM 7). Taken together, the results for the three geographically resolved impact

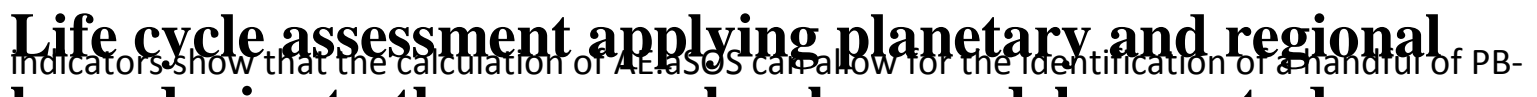
boundaries to the process level: a model case study

450 hotspots within a full product system. Moreover, the results show that the application of aggregated CFs Bjørn, Anders ${ }^{1}$, Sim, Sarah ${ }^{2}$, King, Henry ${ }^{2}$, Patouillard, Laure ${ }^{1}$, Margni, Manuele ${ }^{1}$, Hauschild,

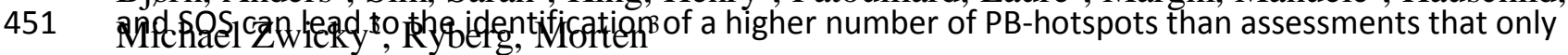

452 cover highly spatially resolved processes.

* corresponding author: Email: anders.bjoern@concordia.ca

Affiliations:

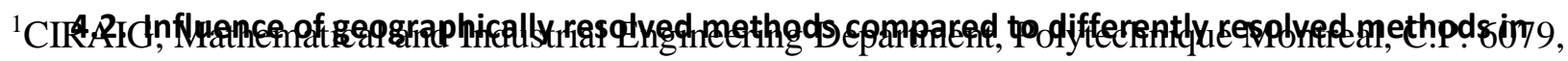

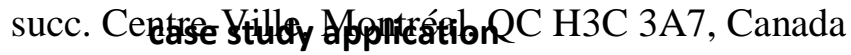

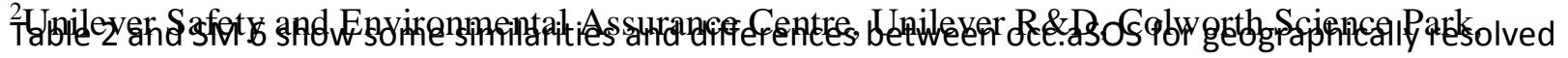
Sharnbrook, MK44 1LQ, UK.

457 methods (Bjørn et al., 2020c, 2020b) and the comparable methods of Ryberg et al. (2018a), which are ${ }^{3}$ Quantitative Sustainability Assessment group, Department of Technology, Management and

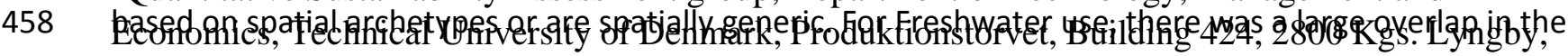
Denmark. processes found to exceed their assigned SOS (occ.aSOS>1), but the geographically resolved method 460 (Bjørn et al., 2020b) identified 16 such processes, whereas the method based on spatial archetypes 461 (Bybefsientalersp18a) only identified 10. The difference can be explained from the different 462 spatialization approaches for the 20 processes in Table 2. For example, five processes belonging to Raw 463 materials and Ingredients and packaging manufacture were spatialized to regions in Europe with highly 464 concentrated economic activity, such as the Rhine basin, for the geographically resolved method (Bjørn 465 et al., 2020b). For the other method (Ryberg et al., 2018a), the same five processes were spatialized to 466 the "humid" archetype. This spatial archetype covers $\approx 70 \%$ of the world's ice-free terrestrial surface, 467 meaning that every unit of value added created within it was allowed a substantially higher freshwater 468 consumption than in the economic hotspot regions in Europe, according to the GVA principle (see Eq. 6). 469 For the indicators related to the nitrogen part of Biogeochemical flows the situation was somewhat 
Bjørn, A., Sim, S., King, H., Patouillard, L., Margni, M., Hauschild, M. Z., \& Ryberg, M. (2020). Life cycle assessment applying planetary and regional boundaries to the process level: a model case study.

opposite, since a higher number of processes were found to exceed their assigned SOS for the spatially generic method (Ryberg et al., 2018a) (29 processes) than for both of the geographically resolved ones (Bjørn et al., 2020c) (20-21 processes). For example, the two palm fruit bunch production processes (see

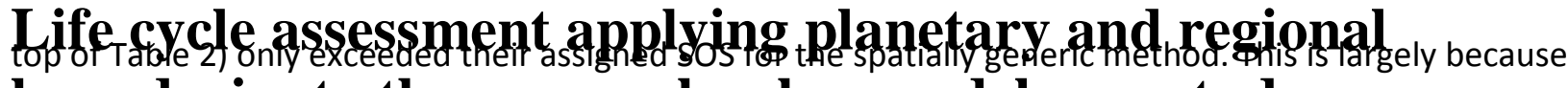
boundaries to the process level: a model case study

474 these processes, for the two geographically resolved methods (Bjørn et al., 2020c), were spatialized to a Bjørn, Anders ${ }^{1}$, Sim, Sarah ${ }^{2}$, King, Henry ${ }^{2}$, Patouillard, Laure ${ }^{1}$, Margni, Manuele ${ }^{1}$, Hauschild,

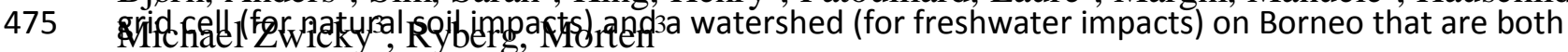

476 characterized by relatively low economic activity, low CFs and high SOS (allowing each unit of value * corresponding author: Email: anders.bjoern@concordia.ca 477 added a relatively high nitrogen emission, according to the GVA principle). Another reason for the

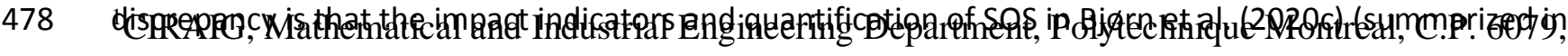

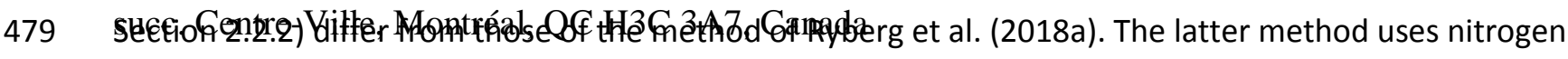

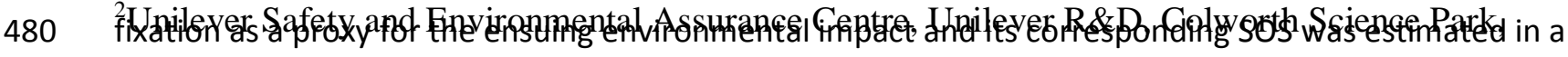
Sharnbrook, MK44 1LQ, UK.

481 back-calculation from a critical nitrogen concentration in surface run-off, as per Steffen et al. (2015).

${ }^{3}$ Quantitative Sustainability Assessment group, Department of Technology, Management and Economics, Technical University of Denmark, Produktionstorvet, Building 424, 2800 Kgs. Lyngby,

483 Phe main contributing processes to the accumulated exceedance of assigned SOS (AE.aSOS) for

Freshwater use were similar for the method based on spatial archetypes (Ryberg et al., 2018a) and the

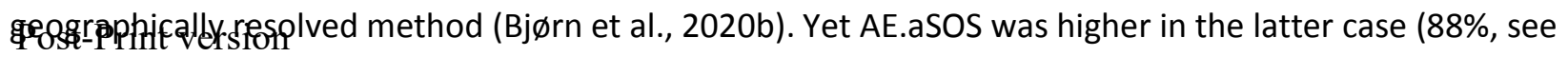

Figure 5), mainly due to a higher contribution from tap water supply to the use stage. This difference is

caused by a higher assigned SOS to that process when spatialized to the "humid" spatial archetype than

when spatialized to the Thames basin in the UK (also leading to a large difference in occ.aSOS, see Table

2). For the nitrogen part of Biogeochemical flows, the spatially generic method (Ryberg et al., 2018a)

yields a higher AE.aSOS than the two geographically resolved methods (Bjørn et al., 2020c, 2020b) (98\%

vs. $73-76 \%$, see Figure 5). This was mainly caused by a high contribution from palm fruit bunch 
Bjørn, A., Sim, S., King, H., Patouillard, L., Margni, M., Hauschild, M. Z., \& Ryberg, M. (2020). Life cycle assessment applying planetary and regional boundaries to the process level: a model case study.

exceed assigned SOS, as elaborated in the previous paragraph). Hence, the use of geographically

resolved methods can point to different PB hotspots than the use of methods that are spatially generic

or based on spatial archetypes.

\section{Life cycle assessment applying planetary and regional boundaries to the process level: a model case study}

4.3. Insights from case study application of a comprehensive set of PB-LCA impact categories Bjørn, Anders ${ }^{1}$, Sim, Sarah ${ }^{2}$, King, Henry ${ }^{2}$, Patouillard, Laure ${ }^{1}$, Margni, Manuele ${ }^{1}$, Hauschild,

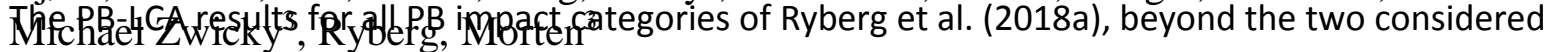

above ("Differently resolved". and "Other impact categories, all spatially generic" in Figure 5) provided * corresponding author: Email: anders.bjoern@concordia.ca

501 new insights: For some impact categories, like Climate change, a large number of processes (up to 40) Affiliations:

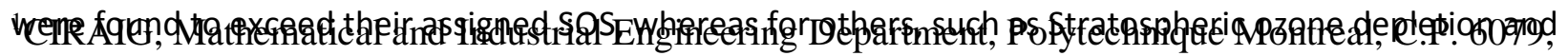

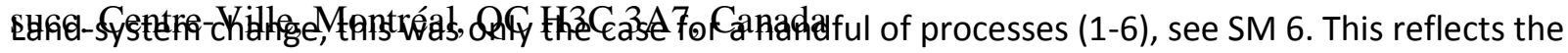

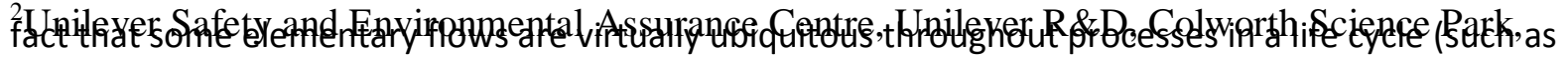

505 Sharnbrook, MK44 1LQ, UK. 2), Whereas others are less common (such as forest transformation). Also, the PB hotspots (high ${ }^{3}$ Quantitative Sustainability Assessment group, Department of Technology, Management and

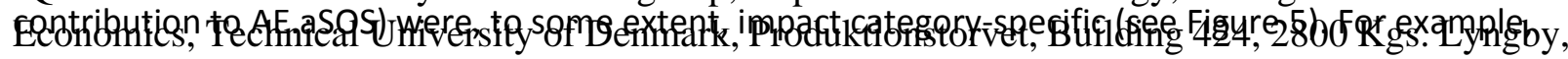

Denmark.

507 Agrochemicals only had a high contribution to the phosphorous part of Biogeochemical flows and

508 Energy and infrastructure processes only accounted for a large part of AE.aSOS for Stratospheric ozone

509 depklełpinandrAtmospheric aerosol loading (see Figure 5). Also, AE.aSOS was observed to span from 30\%

510 for Stratospheric ozone depletion to close to $100 \%$ for Climate change (see Figure 5). This difference is

511 consistent with the fact that the PB for the former impact category is far from being exceeded by global

512 emissions, while the PB for the latter has been exceeded (Steffen et al., 2015). The case study

513 application shows that the process-level approach is applicable to all PB impact categories. The observed

514 differences in the results between impact categories reaffirms the importance of covering a

515 comprehensive list of PB impact categories in the pursuit of an environmentally sustainable product life

516 cycle. 
Bjørn, A., Sim, S., King, H., Patouillard, L., Margni, M., Hauschild, M. Z., \& Ryberg, M. (2020). Life cycle assessment applying planetary and regional boundaries to the process level: a model case study. approach

\section{Life cycle assessment applying planetary and regional boundaries to the process level: a model case study}

offer novel uses and insights for practitioners and decision-makers. Instead of assessing whether a Bjørn, Anders ${ }^{1}$, Sim, Sarah ${ }^{2}$, King, Henry ${ }^{2}$, Patouillard, Laure ${ }^{1}$, Margni, Manuele ${ }^{1}$, Hauschild, Rifiphuct lsytem

524 used to identify individual processes exceeding their assigned SOS and subsequently relate this * corresponding author: Email: anders.bjoern@concordia.ca

exceedance to the life-cycle impact. Such an assessment allows decision-makers to identify priorities in Affiliations:

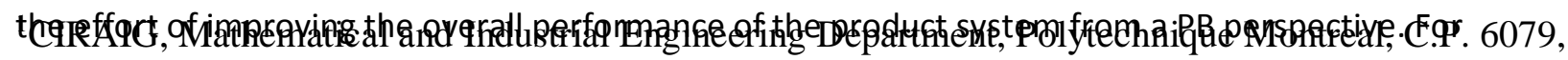

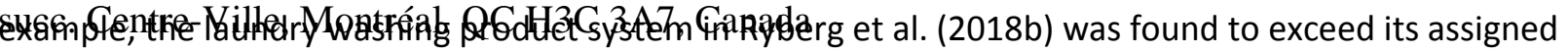

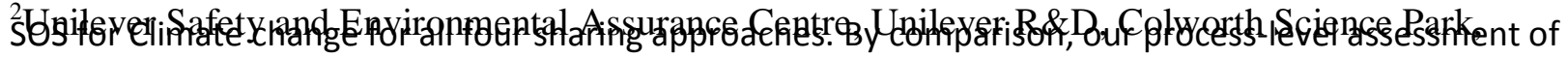
Sharnbrook, MK441LQ, UK.

a similar case study found that 40 of the 61 selected processes exceeded their assigned SOS for Climate ${ }^{3}$ Quantitative Sustainability Assessment group, Department of Technology, Management and 531 Denmark.

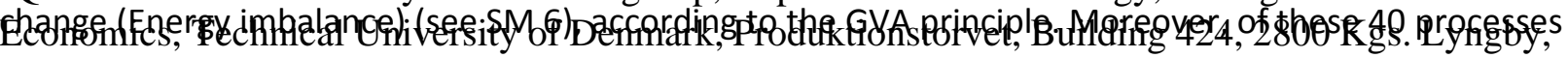

7). Identification of such PB hotspots could provide the focus for urgent improvement efforts towards a prostuptifystemilhose main sources of environmental impact are below their assigned SOS.

\subsubsection{Uncertainties}

Process-level assessments capture spatial variations in CFs and SOS for regional impact categories. It may therefore be less uncertain than the common PB-LCA approach that only covers global CFs and SOS.

Yet, process-level assessments come with a unique set of uncertainties. First, some techniques for spatializing processes to spatial units (e.g., watersheds or grid cells) involve uncertainty. For example, several processes of this case study were assigned to spatial units in which they are relatively likely (but 541 not fully certain) to be situated in, according to geographically resolved production statistics (see Section 
Bjørn, A., Sim, S., King, H., Patouillard, L., Margni, M., Hauschild, M. Z., \& Ryberg, M. (2020). Life cycle assessment applying planetary and regional boundaries to the process level: a model case study.

2.3.2). Further, when processes are spatialized to a country or a continent (instead of a spatial unit)

there is a loss of information on spatial variability in CFs, SOS and parameters used to assign SOS within such aggregated regions. The related uncertainties may be of special concern for large aggregated

\section{Life cycle assessment applying planetary and regional LitcA $_{\text {egs }}$ boundaries to the process level: a model case study}

studies may use uncertainty propagation (Ryberg et al., 2018b) to understand the robustness of results

Bjørn, Anders ${ }^{1}$, Sim, Sarah ${ }^{2}$, King, Henry ${ }^{2}$, Patouillard, Laure ${ }^{1}$, Margni, Manuele ${ }^{1}$, Hauschild,

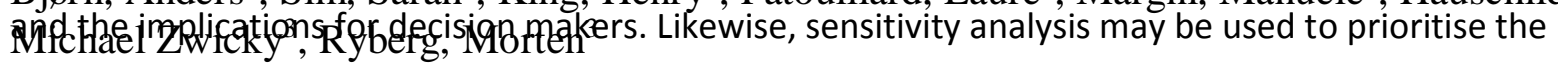

collection of spatial process data (Patouillard et al., 2019) in order to reduce uncertainty.

* corresponding author: Email: anders.bjoern@concordia.ca

Affiliations:

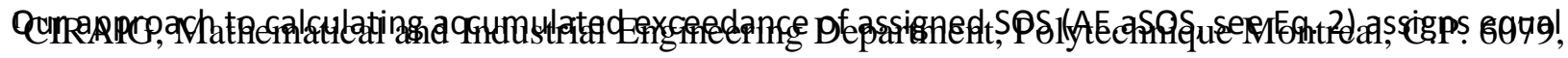

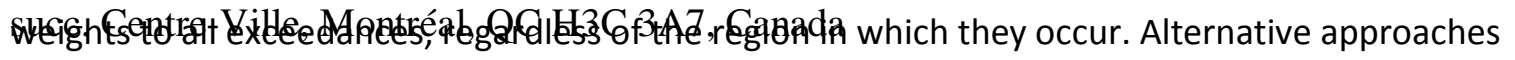

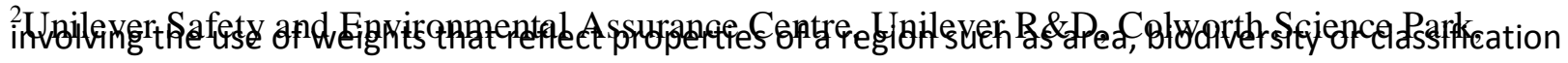

Sharnbrook, MK44 1LQ, UK.

as keystone region (Gleeson et al., 2020) (i.e., being of high importance to Earth-system stability) may

${ }^{3}$ Quantitative Sustainability Assessment group, Department of Technology, Management and

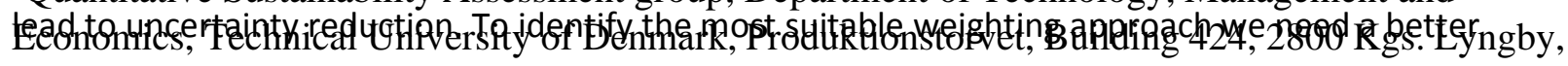

Denmark.

understanding of the mechanisms by which exceedance of regional boundaries may lead to

destabilization of the Earth system (Bjørn et al., 2019; Brook et al., 2013; Lenton and Williams, 2013).

Post-Print version

\subsubsection{Recommendations to software and database developers}

Ideally, practitioners should be able to conduct process-level PB-LCA in LCA software, but this is

currently not possible. To ensure correct links between spatialized elementary flows and geographically

resolved CFs, we encourage inventory database and software developers to follow the recent

recommendations of the UNEP-SETAC Life Cycle Initiative working group on the harmonization of LCIA

regionalization (Mutel et al., 2019). Specifically for PB-LCA, we furthermore encourage inventory

database developers, such as Ecoinvent (Wernet et al., 2016), to: 1) create a database version in which

processes occurring in the same production facility are merged. This would save time, negating the need 
Bjørn, A., Sim, S., King, H., Patouillard, L., Margni, M., Hauschild, M. Z., \& Ryberg, M. (2020). Life cycle assessment applying planetary and regional boundaries to the process level: a model case study.

8

568

569

570

571

572

573

22

for manual merging of processes after the calculation of inventory results (see SM 3.2); 2) Ensure that processes labelled as unit processes are, in fact, not system processes (i.e., having "cradle to gate" system boundaries). In carrying out the case study, we discovered several such mislabels (see SM 4), Life cycle assessment applying planetary and regional boundaries to the process level: a model case study

Bjørn, Anders ${ }^{1}$, Sim, Sarah ${ }^{2}$, King, Henry ${ }^{2}$, Patouillard, Laure ${ }^{1}$, Margni, Manuele ${ }^{1}$, Hauschild,

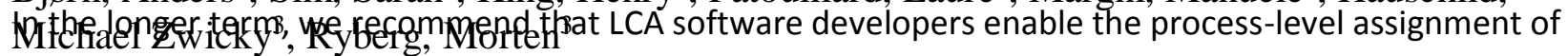

SOS and the subsequent calculation of occ.aSOS and AE.aSOS. This would require each link between an * corresponding author: Email: anders.bjoern@concordia.ca

elementary flow and a CF (whether global or covering a spatial unit or an aggregated region) to be Affiliations:

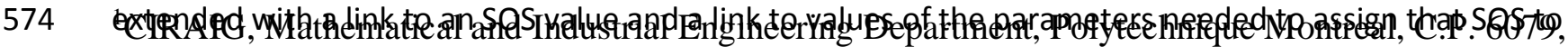

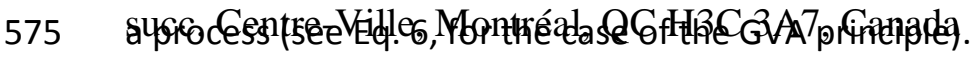

$576{ }^{2}$ Unilever Safety and Environmental Assurance Centre, Unilever R\&D, Colworth Science Park, 577 4.4.4. Future research needs

${ }^{3}$ Quantitative Sustainability Assessment group, Department of Technology, Management and

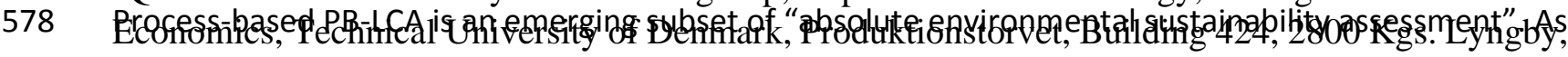
579 such, the broad recommendations for addressing methodological limitations presented in the review of 580 Bjørn et al. (2020a) also apply here. For example, SOS estimates should reflect the latest scientific

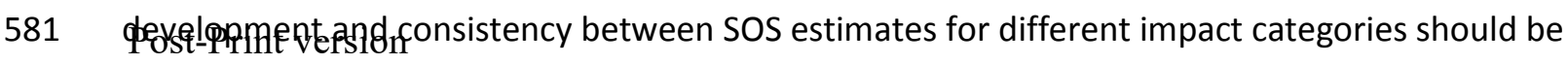
582 ensured. Also, the exceedance of one planetary or regional boundary (e.g., for Climate change) may 583 change the positions of other boundaries (e.g., for Freshwater use) (Lade et al., 2020; Steffen et al., 5842015 ) and there is a need to quantify these interactions (Bjørn et al., 2019).

In this paper we applied the process-level approach with geographically resolved PB-LCA impact 587 indicators for Freshwater use and the nitrogen part of Biogeochemical flows. There is a need for also 588 developing geographically resolved methods for the phosphorous part of Biogeochemical flows and for 589 Land-system change (see Bjørn et al. (2019) for challenges and opportunities for the latter). Likewise, 
Bjørn, A., Sim, S., King, H., Patouillard, L., Margni, M., Hauschild, M. Z., \& Ryberg, M. (2020). Life cycle assessment applying planetary and regional boundaries to the process level: a model case study.

new PB-LCA methods should be developed as PB science evolves, for example with respect to Biosphere

Life cycle assessment applying planetary and regional and purpos. boundaries to the process level: a model case study

However, a principle related to need-fulfilment may be more acceptable amongst a study's stakeholders Bjørn, Anders ${ }^{1}$, Sim, Sarah ${ }^{2}$, King, Henry ${ }^{2}$, Patouillard, Laure ${ }^{1}$, Margni, Manuele ${ }^{1}$, Hauschild,

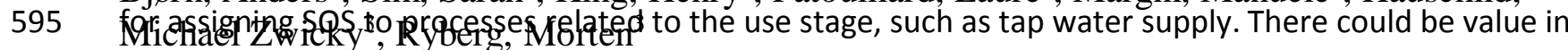
596 comparing the application of multiple sharing principles (ten were identified in Bjørn et al. (2020a)) to * corresponding author: Email: anders.bjoern@concordia.ca 597 process-level PB-LCA, to understand the practicality of application and the sensitivity of results to the

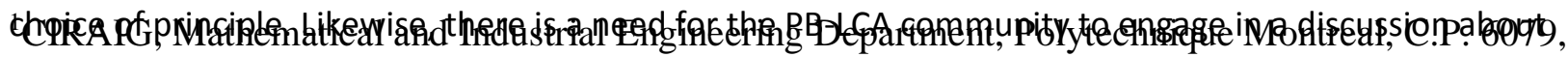

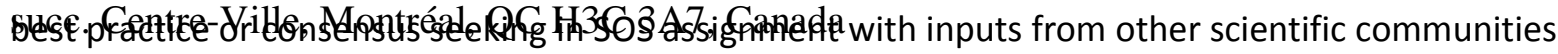

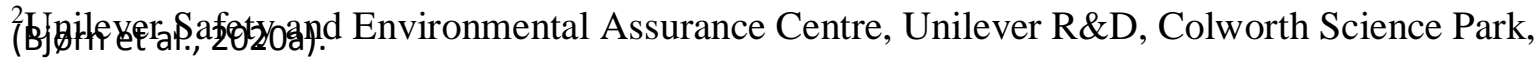

Sharnbrook, MK44 1LQ, UK.

${ }^{3}$ Quantitative Sustainability Assessment group, Department of Technology, Management and

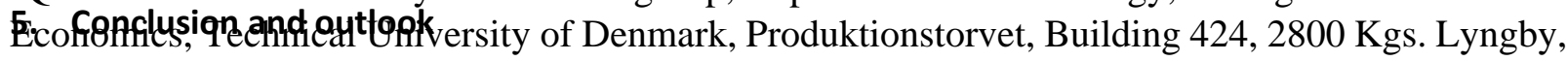

Denmark.

an extended process-level approach that covers a comprehensive set of impact categories. The case

stydizapplication shows that a process-level approach may point to more specific priority areas within a

product system than the common PB-LCA approach and that related uncertainties should be quantified

in future applications. As PB-LCA methods continue to evolve and mature, the complementary nature of

these approaches and conventional LCA will warrant further consideration. In particular, the potential 
Bjørn, A., Sim, S., King, H., Patouillard, L., Margni, M., Hauschild, M. Z., \& Ryberg, M. (2020). Life cycle assessment applying planetary and regional boundaries to the process level: a model case study.

\section{Acknowledgements}

We thank Maxime Agez, Polytechnique Montréal, for extracting GVA data from Exiobase and for

assisting with the linking of Ecoinvent processes and Exiobase products and the merging of Ecoinvent

\section{Life cycle assessment applying planetary and regional} boundaries to the process level: a model case study

for their thoughtful comments. This study received funding from Mitacs and Unilever.

Bjørn, Anders ${ }^{1}$, Sim, Sarah ${ }^{2}$, King, Henry ${ }^{2}$, Patouillard, Laure ${ }^{1}$, Margni, Manuele ${ }^{1}$, Hauschild, Michael Zwicky ${ }^{3}$, Ryberg, Morten ${ }^{3}$

\section{References}

* corresponding author: Email: anders.bjoern@concordia.ca

Agez, M., Wood, R., Margni, M., Strømman, A.H., Samson, R., Majeau-Bettez, G., 2020. Hybridization of Affiliations:

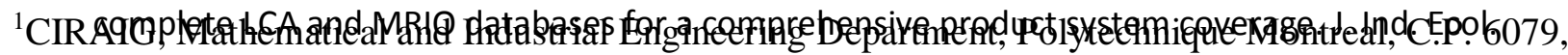

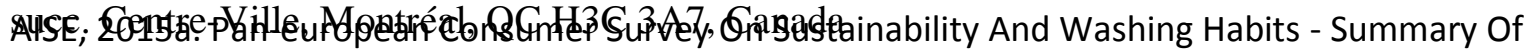

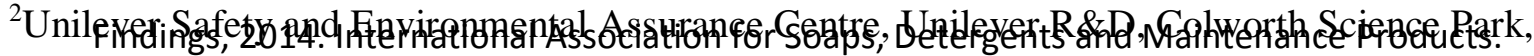

Sharnbrook, MK44 1LQ, UK.

AISE, 2015b. PEF Screening Report in the Context of the EU Product Environmental Footprint Category

${ }^{3}$ Quantitative Sustainability Assessment group, Department of Technology, Management and

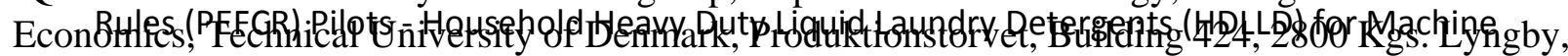
Denmark. Wash. International Association for Soaps, Detergents and Maintenance Products.

Bjørn, A., Chandrakumar, C., Boulay, A.-M., Doka, G., Fang, K., Gondran, N., Hauschild, M.Z., Kerkhof, A.,

Post-Sipfigrt verSlargni, M., Mclaren, S., Mueller, C., Owsianiak, M., Peters, G., Roos, S., Sala, S., Sandin, G., Sim, S., Vargas-Gonzalez, M., Ryberg, M., 2020a. Review of life-cycle based methods for absolute environmental sustainability assessment and their applications. Environ. Res. Lett. 15. https://doi.org/https://doi.org/10.1088/1748-9326/ab89d7

Bjørn, A., Sim, S., Boulay, A.-M., King, H., Clavreul, J., Lam, W.Y., Barbarossa, V., Bulle, C., Margni, M., 2020b. A planetary boundary-based method for freshwater use in life cycle assessment: Development and application to tomato production case study. Ecol. Indic. 110, 105865.

Bjørn, A., Sim, S., King, H., Keys, P., Wang-Erlandsson, L., Cornell, S., Margni, M., Bulle, C., 2019. Challenges and opportunities towards improved application of the planetary boundary for Land- 
Bjørn, A., Sim, S., King, H., Patouillard, L., Margni, M., Hauschild, M. Z., \& Ryberg, M. (2020). Life cycle assessment applying planetary and regional boundaries to the process level: a model case study.

system change in life cycle assessment of products. Sci. Total Environ. 696, 133964.

Bjørn, A., Sim, S., King, H., Margni, M., Henderson, A., Payen, S., Bulle, C., 2020c. A comprehensive

Post-Systainapility assessment framework. Ecol. Econ. 114, 218-226.

https://doi.org/10.1016/j.ecolecon.2015.04.008

GFW, 2019. Oil palm concessions. Global Forest Watch [WWW Document]. URL

http://data.globalforestwatch.org/datasets/20398d4dc36e47bd92b559786670f270_1 (accessed

5.14.19).

Gleeson, T., Erlandsson, L.W., Zipper, S.C., Porkka, M., Jaramillo, F., Gerten, D., Fetzer, I., Cornell, S.E., Piemontese, L., Gordon, L., Rockström, J., Oki, T., Sivapalan, M., Y., W., Brauman, K.A., Flörke, M., Bierkens, M.F.P., Lehner, B., Keys, P., Kummu, M., Wagener, T., Dadson, S., Troy, T.J., Steffen, W., Falkenmark, M., Famiglietti, J.S., 2020. The water planetary boundary: interrogation and revision. 
Bjørn, A., Sim, S., King, H., Patouillard, L., Margni, M., Hauschild, M. Z., \& Ryberg, M. (2020). Life cycle assessment applying planetary and regional boundaries to the process level: a model case study.

One Earth 2, 223-234.

Kahiluoto, H., Kuisma, M., Kuokkanen, A., Mikkilä, M., Linnanen, L., 2015. Local and social facets of planetary boundaries: right to nutrients. Environ. Res. Lett. 10, 104013.

\section{Life ,CYcle assessment, applying planetary and regional anduct and boundaries to the process level: a model case study}

Human Development Index over 1990 - 2015. Sci. data 5, 180004.

Bjørn, Anders ${ }^{1}$, Sim, Sarah ${ }^{2}$, King, Henry ${ }^{2}$, Patouillard, Laure ${ }^{1}$, Margni, Manuele ${ }^{1}$, Hauschild,

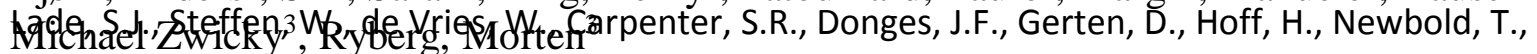

Richardson, K., Rockström, J., 2020. Human impacts on planetary boundaries amplified by Earth * corresponding author: Email: anders.bjoern@concordia.ca

system interactions. Nat. Sustain. 3, 119-128. https://doi.org/10.1038/s41893-019-0454-4 Affiliations:

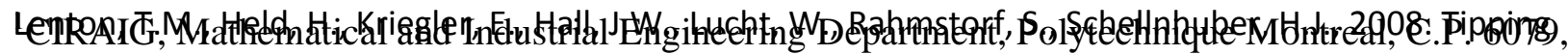

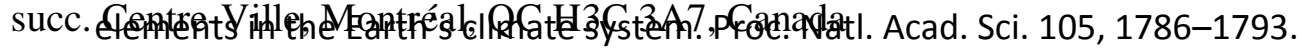

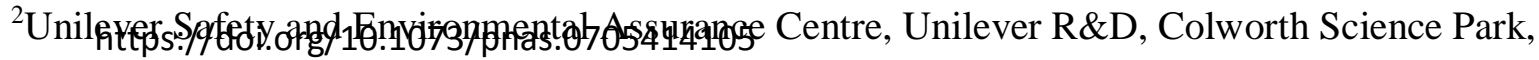

Sharnbrook, MK44 1LQ, UK.

673 Lenton, T.M., Williams, H.T.P., 2013. On the origin of planetary-scale tipping points. Trends Ecol. Evol.

${ }^{3}$ Quantitative Sustainability Assessment group, Department of Technology, Management and

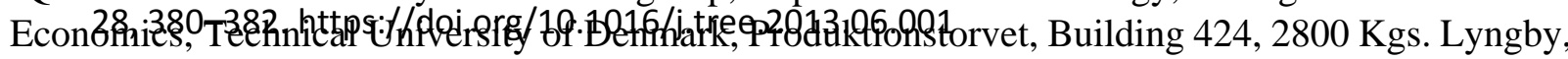

Renmark. C., Liao, X., Patouillard, L., Bare, J., Fantke, P., Frischknecht, R., Hauschild, M., Jolliet, O., Souza,

D.M. De, Laurent, A., Pfister, S., 2019. Overview and recommendations for regionalized life cycle

677 Post-Implpte assiossment. Int. J. Life Cycle Assess. 24, 856-865.

678 Patouillard, L., Bulle, C., Querleu, C., Maxime, D., Osset, P., Margni, M., 2018. Critical review and

practical recommendations to integrate the spatial dimension into life cycle assessment. J. Clean.

Prod. 177, 398-412. https://doi.org/10.1016/j.jclepro.2017.12.192

Patouillard, L., Collet, P., Lesage, P., Tirado Seco, P., Bulle, C., Margni, M., 2019. Prioritizing

regionalization efforts in life cycle assessment through global sensitivity analysis: a sector metaanalysis based on ecoinvent v3. Int. J. Life Cycle Assess. 24, 2238-2254.

https://doi.org/10.1007/s11367-019-01635-5

685 PRé, 2019. SimaPro V8.5.2.0. 
Bjørn, A., Sim, S., King, H., Patouillard, L., Margni, M., Hauschild, M. Z., \& Ryberg, M. (2020). Life cycle assessment applying planetary and regional boundaries to the process level: a model case study.

Randers, J., 2012. Greenhouse gas emissions per unit of value added ("GEVA") - A corporate guide to voluntary climate action. Energy Policy 48, 46-55.

Rocha, J., Peterson, G., Bodin, Ö., Levin, S.A., 2018. Cascading regime shifts within and across scales.

Lifectercle assessment applying planetary and regional boundaries to the process level: a model case study

690 Rockström, J., Steffen, W., Noone, K., Persson, A., Chapin, F.S., Lambin, E.F., Lenton, T.M., Scheffer, M., Bjørn, Anders ${ }^{1}$, Sim, Sarah ${ }^{2}$, King, Henry ${ }^{2}$, Patouillard, Laure ${ }^{1}$, Margni, Manuele ${ }^{1}$, Hauschild,

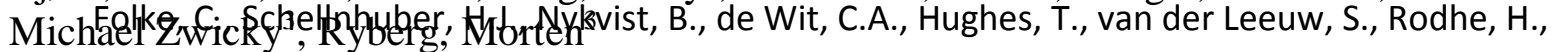

Sorlin, S., Snyder, P.K., Costanza, R., Svedin, U., Falkenmark, M., Karlberg, L., Corell, R.W., Fabry,

* corresponding author: Email: anders.bjoern@concordia.ca

V.t., Hansen, J., Walker, B., Liverman, D., Richardson, K., Crutzen, P., Foley, J.A., 2009a. A safe Affiliations:

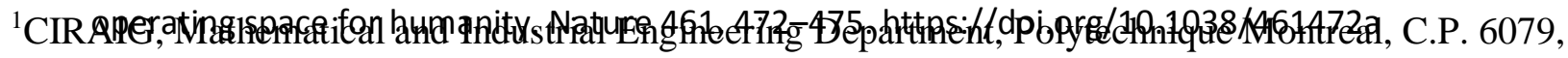

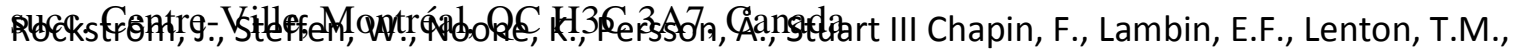

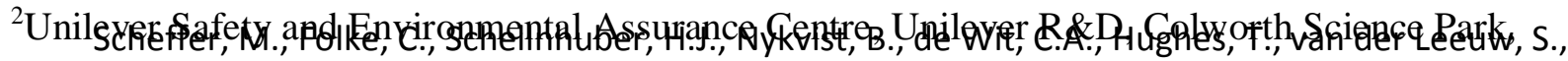

Sharnbrook, MK441LQ, UK.

Rodhe, H., Sörlin, S., Snyder, P.K., Costanza, R., Svedin, U., Falkenmark, M., Karlberg, L., Corell,

${ }^{3}$ Quantitative Sustainability Assessment group, Department of Technology, Management and

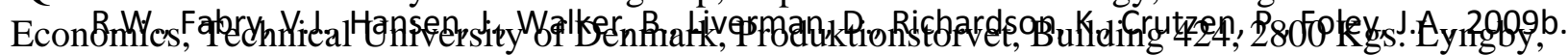

Denmark.

Ryberg, M.W., Owsianiak, M., Clavreul, J., Mueller, C., Sim, S., King, H., Hauschild, M.Z., 2018a. How to

Post-Pripg adesolyte sustainability into decision-making: An industry case study using a Planetary Boundary-based methodology. Sci. Total Environ. 634, 1406-1416. https://doi.org/10.1016/j.scitotenv.2018.04.075

Ryberg, M.W., Owsianiak, M., Richardson, K., Hauschild, M.Z., 2016. Challenges in implementing a Planetary Boundaries based Life-Cycle Impact Assessment methodology. J. Clean. Prod. 139, 450459. https://doi.org/http://dx.doi.org/10.1016/j.jclepro.2016.08.074

Ryberg, M.W., Richardson, K., Hauschild, M.Z., 2018b. Development of a life-cycle impact assessment methodology linked to the Planetary Boundaries framework. Ecol. Indic. 88, 250-262. 
Bjørn, A., Sim, S., King, H., Patouillard, L., Margni, M., Hauschild, M. Z., \& Ryberg, M. (2020). Life cycle assessment applying planetary and regional boundaries to the process level: a model case study.

Stadler, K., Wood, R., Bulavskaya, T., Södersten, C.J., Simas, M., Schmidt, S., Usubiaga, A., AcostaFernández, J., Kuenen, J., Bruckner, M., Giljum, S., Lutter, S., Merciai, S., Schmidt, J.H., Theurl, M.C.,

\section{Life cycle assessment applying planetary and regional} boundaries to the process level: a model case study

Tables. J. Ind. Ecol. 22, 502-515. https://doi.org/10.1111/jiec.12715

Bjørn, Anders ${ }^{1}$, Sim, Sarah ${ }^{2}$, King, Henry ${ }^{2}$, Patouillard, Laure ${ }^{1}$, Margni, Manuele ${ }^{1}$, Hauschild,

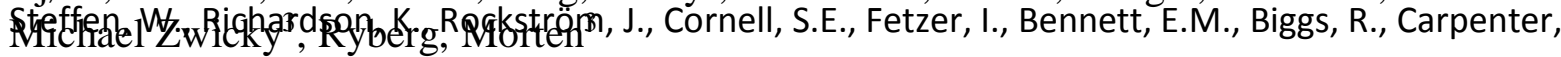

S.R., de Vries, W., de Wit, C.A., Folke, C., Gerten, D., Heinke, J., Mace, G.M., Persson, L.M.,
* corresponding author: Email: anders.bjoern@concordia.ca

Ramanathan, V., Reyers, B., Sorlin, S., 2015. Planetary boundaries: Guiding human development on Affiliations:

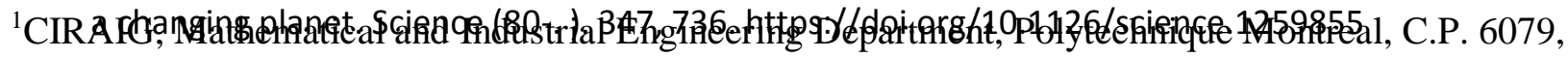

suefnetentr,

${ }^{2}$ Unilaverbasetve

Sharnbrook, MK44 1LQ, UK.

Willett, W., Rockström, J., Loken, B., Springmann, M., Lang, T., Vermeulen, S., Garnett, T., Tilman, D.,

${ }^{3}$ Quantitative Sustainability Assessment group, Department of Technology, Management and

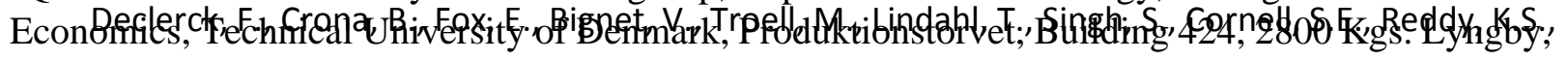

Denmark.

Naräin, S., Nishtar, S., Murray, C.J.L., 2019. The Lancet Commissions Food in the Anthropocene: the EAT - Lancet Commission on healthy diets from sustainable food systems. Lancet 393, 447-492.

Post-Ptrtipit:k/deiorg/10.1016/S0140-6736(18)31788-4 